\title{
Control of Long-Term Plasticity by Glutamate Transporters
}

\author{
Silvana Valtcheva ${ }^{* \dagger}$ and Laurent Venance* \\ Dynamics and Pathophysiology of Neuronal Networks Team, Center for Interdisciplinary Research in Biology (CIRB), Collège \\ de France, CNRS UMR7241/INSERM U1050, Paris, France
}

Activity-dependent long-term changes in synaptic strength constitute key elements for learning and memory formation. Long-term plasticity can be induced in vivo and ex vivo by various physiologically relevant activity patterns. Depending on their temporal statistics, such patterns can induce long-lasting changes in the synaptic weight by potentiating or depressing synaptic transmission. At excitatory synapses, glutamate uptake operated by excitatory amino acid transporters (EAATs) has a critical role in regulating the strength and the extent of receptor activation by afferent activity. EAATs tightly control synaptic transmission and glutamate spillover. EAATs activity can, therefore, determine the polarity and magnitude of long-term plasticity by regulating the spatiotemporal profile of the glutamate transients and thus, the glutamate access to

Edited by:

Clive R. Bramham,

University of Bergen, Norway

Reviewed by:

Michel Baudry,

Western University of Health

Sciences, United States

Vidar Jensen,

University of Oslo, Norway

*Correspondence:

Silvana Valtcheva

silvana.valtcheva@nyumc.org

Laurent Venance

laurent.venance@college-de-france.fr

${ }^{\dagger}$ Present address:

Silvana Valtcheva,

Departments of Otolaryngology,

Neuroscience and Physiology,

Skirball Institute, Neuroscience

Institute, New York University School of Medicine, New York, NY,

United States

Received: 18 December 2018 Accepted: 12 March 2019

Published: 09 April 2019

Citation:

Valtcheva $S$ and Venance $L$ (2019) Control of Long-Term

Plasticity by Glutamate Transporters.

Front. Synaptic Neurosci. 11:10.

doi: 10.3389/fnsyn.2019.00010 pre- and postsynaptic receptors. Here, we summarize compelling evidence that EAATs regulate various forms of long-term synaptic plasticity and the consequences of such regulation for behavioral output. We speculate that experience-dependent plasticity of EAATs levels can determine the sensitivity of synapses to frequency- or time-dependent plasticity paradigms. We propose that EAATs contribute to the gating of relevant inputs eligible to induce long-term plasticity and thereby select the operating learning rules that match the physiological function of the synapse adapted to the behavioral context.

Keywords: synaptic plasiticty, excitatory amino acid transporters, glutamate uptake, astrocytes, spike-timing dependent plasticity, neuro-glia crosstalk, glutamate spillover

\section{INTRODUCTION}

Information processing at central synapses is governed by two main neural coding strategies: integration and coincidence detection, which rely on the rate- and spike-time coding, respectively (deCharms and Zador, 2000; Brette, 2015). Accordingly, the ability of synapses to undergo long-term changes in synaptic weight have been investigated in vivo and ex vivo using two main types of cell conditioning paradigms: rate-based and spike-timing-based protocols (Malenka and Bear, 2004; Sjöström et al., 2008; Feldman, 2012). The induction of long-term potentiation (LTP) or depression (LTD), following different cell conditioning paradigms, is assessed by the relative change in the magnitude of postsynaptic responses. The induction of long-term synaptic plasticity at glutamatergic synapses requires the activation of presynaptic and postsynaptic glutamate receptors, situated at synaptic, perisynaptic and extrasynaptic sites (Asztely et al., 1997; Bergles and Jahr, 1997; Bergles et al., 1997; Min et al., 1998; Rusakov and Kullmann, 1998; Lehre and Rusakov, 2002; Zheng et al., 2008; Figure 1). The timing of activation of glutamate receptors is expected to be proportional to their distance from the presynaptic release site (Attwell and Gibb, 2005). There is a critical role of glutamate diffusion in determining the balance of receptor activation. High-affinity membrane glutamate transporters (also named excitatory amino acid transporters, EAATs) 

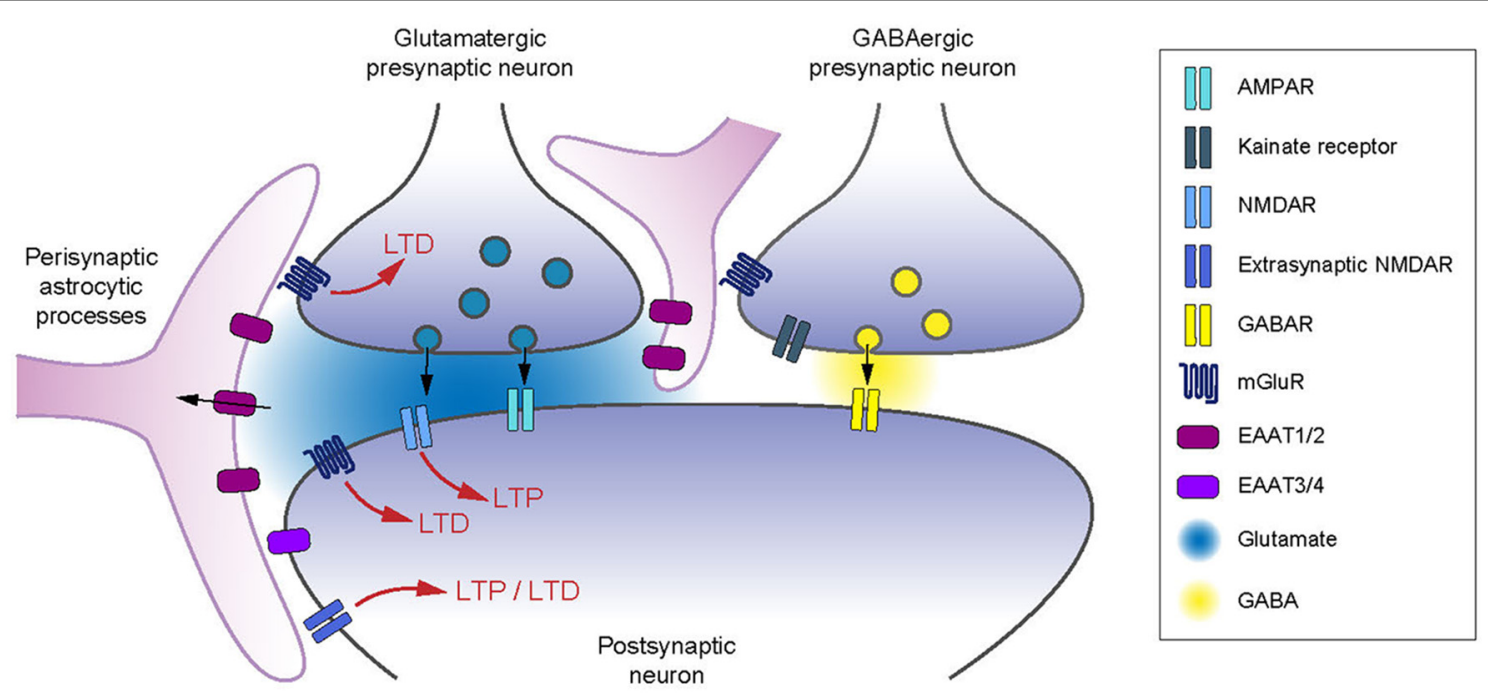

FIGURE 1 | Excitatory amino acid transporters (EAATs) control of receptors involved in long-term synaptic plasticity. EAATs control the activation of pre- and postsynaptic glutamate receptors, as well as the spread of glutamate to neighboring inhibitory neurons. EAAT2 controls the induction of long-term plasticity relying on presynaptic (Omrani et al., 2009) and postsynaptic mGluRs (Brasnjo and Otis, 2001; Valtcheva and Venance, 2016) and postsynaptic NMDARs (Katagiri et al., 2001; Massey et al., 2004; Wong et al., 2007; Scimemi et al., 2009; Valtcheva and Venance, 2016). Astrocytic coverage of neurons controls the activation of presynaptic type-III mGluRs or kainate receptors on GABAergic terminals (Piet et al., 2004; Bonfardin et al., 2010).

control the degree to which glutamate receptors located in the perisynaptic space or outside the synaptic cleft are activated following each release event (Bergles et al., 1997; Min et al., 1998; Zheng et al., 2008; Vandenberg and Ryan, 2013). The glutamate uptake process is electrogenic and is driven by the ion gradients of $\mathrm{K}^{+}$and $\mathrm{Na}^{+}$(Zerangue and Kavanaugh, 1996; Levy et al., 1998; Owe et al., 2006). EAATs have similar affinities for glutamate as glutamate receptors (Arriza et al., 1994) and their transport cycle is slow relative to the time course of glutamate in the synaptic cleft (Clements et al., 1992; Wadiche et al., 1995; Bergles and Jahr, 1998). Therefore, the main role of EAATs is to terminate the glutamate transient by primary acting as glutamate buffers followed by active transport. While during sparse activation of synapses, glutamate is likely cleared from the synaptic cleft by diffusion instead of active transport (Helassa et al., 2018), EAATs appear as key players for plasticity induction by controlling the spatiotemporal activation of glutamatergic receptors during episodes of high neuronal activity.

EAATs are constituted by five subtypes, named EAAT1-5 (Danbolt, 2001). EAAT type-1 (EAAT1) and type-2 (EAAT2) are mainly expressed in glial cells. EAAT1 is mostly expressed by Bergmann glia cells but is also found in other brain regions (Arriza et al., 1994; Rothstein et al., 1994; Chaudhry et al., 1995; Lehre et al., 1995; Wadiche and Kavanaugh, 1998). EAAT2 is specifically expressed in perisynaptic astrocytic processes ensheathing synaptic complexes, but not in astrocytic cell bodies (Danbolt et al., 1992; Rothstein et al., 1994; Lehre et al., 1995; Furuta et al., 1997; Levy et al., 1998; Minelli et al., 2001; Holmseth et al., 2009). EAAT2 can also be found in some excitatory neurons in hippocampus and cortex but its physiological role remains uncertain based on its distribution (not concentrated at synapses) and its low level of expression
( $\sim 10 \%$ of astrocytic EAAT2; Chen et al., 2004; Furness et al., 2008; Melone et al., 2009, 2011; Petr et al., 2015; Danbolt et al., 2016; Rimmele and Rosenberg, 2016). EAAT type-3 (EAAT3) and EAAT type-4 (EAAT4) are found in neurons at postsynaptic sites (Rothstein et al., 1994; Fairman et al., 1995; Lehre et al., 1995; Furuta et al., 1997; Conti et al., 1998). EAAT4 is expressed by cerebellar Purkinje cells in particular on extrasynaptic sites (Tanaka et al., 1997; Dehnes et al., 1998). Finally, EAAT type-5 (EAAT5) is expressed in the photoreceptors, bipolar and amacrine cells of the retina and has been suggested to mainly act as glutamate-activated chloride channel to control the excitability of retinal neurons (Eliasof and Jahr, 1996; Arriza et al., 1997; Veruki et al., 2006; Schneider et al., 2014).

Numerous studies have shown that both astrocytic and neuronal EAATs regulate the output of activity-dependent long-term synaptic plasticity triggered by different cell conditioning paradigms. Pharmacological or genetic alteration of EAATs activity can either facilitate or impair rate-based synaptic plasticity (Brasnjo and Otis, 2001; Katagiri et al., 2001; Massey et al., 2004; Wang et al., 2006; Wong et al., 2007; Omrani et al., 2009; Bellini et al., 2018). Spike-timingbased cell-conditioning paradigms such as spike-timingdependent plasticity (STDP) reveal subtler multidimensional regulation of synaptic plasticity by EAATs. STDP is a Hebbian synaptic learning rule accounting for experience-dependent changes in neural networks (Sjöström et al., 2008; Feldman, 2012), which depends on pre- and post-synaptic activity. Besides the change in synaptic weight, STDP rules are described by the permissive temporal window ( $\left.\Delta \mathrm{t}_{\text {STDP }}\right)$ for plasticity expression. If pre- and post-synaptic activity occur at $\Delta \mathrm{t}_{\mathrm{STDP}}$ beyond a few tens of milliseconds, it does not generally trigger long-term synaptic efficacy changes, 
and, therefore, these events are considered as uncorrelated. Altering glutamate uptake by up- or downregulation of the astrocytic EAAT2 has an effect on both STDP expression and the temporal range of its permissive window (Valtcheva and Venance, 2016).

Here, we review recent findings on the control of long-term synaptic plasticity by EAATs and we discuss how alterations of glutamate transport affect behavior. Finally, we focus on the physiological regulation of EAATs by different forms of experience and speculate on how this might shape the sensitivity of synapses to undergo different forms of long-term plasticity.

\section{EAATS CONTROL OF LONG-TERM SYNAPTIC PLASTICITY DEPENDS ON THE CELL CONDITIONING PARADIGM}

EAATs exert differential control on long-term synaptic plasticity depending on the cell conditioning paradigm, i.e., rate- vs. spiketiming protocols. EAATs regulate the expression and magnitude of rate-based synaptic plasticity, whereas EAATs control the expression and the temporal window of spike-timing-based synaptic plasticity.

Pharmacological or genetic targeting of EAATs alters the magnitude of plasticity induced with rate-based protocols such as low- and high-frequency stimulation (LFS and HFS, respectively) or theta-burst stimulation (TBS; Figures 2, 3; Table 1). Inhibition of glutamate uptake with bath application of threo- $\beta$-benzyloxyaspartic acid (TBOA), a broad-spectrum non-transportable EAATs blocker, or with trans-4-carboxy-Lproline (t-PDC), a transportable inhibitor, promotes LFS-LTD in layer II/III of perirhinal cortex of adult rats while no plasticity is observed in control conditions (Massey et al., 2004; Figure 3A). Similarly, TBOA bath application in acute brain slices or intracerebroventricular infusion in vivo also promotes LFS-LTD in the CA1 region of the hippocampus of adult rats, while no plasticity is observed after LFS in control conditions in vivo and ex vivo (Wong et al., 2007; Figure 3A). Blockade of glutamate transport with TBOA also increases single-cell LTD magnitude in cerebellar Purkinje cells in juvenile rats, triggered by HFS of the parallel fibers paired with Purkinje cell depolarization (Brasnjo and Otis, 2001; Figures 2A, 3A). Genetic deletion of astrocytic EAAT2 results in impaired HFS-LTP, but has no effect on LFS-LTD, in brain slices of the stratum radiatum of mice (Katagiri et al., 2001; Figures 2B, 3A). Pharmacological blockade with the EAAT2 specific inhibitor dihydrokainic acid (DHK) decreases TBS-LTP magnitude of C-fiber evoked field potentials in the spinal dorsal horn of anesthetized rats (Wang et al., 2006; Figure 3A). TBS-LTP in the hippocampal CA1 region is impaired in mice lacking neuronal EAAT3 (Scimemi et al., 2009; Figure 3A). Overexpression of EAAT2 protein levels via i.p. treatment with the beta-lactam antibiotic ceftriaxone (Rothstein et al., 2005) prevents the expression of LFS-LTD and decreases the magnitude of HFS-LTP at the hippocampal mossy fibers-CA3 synapse (Omrani et al., 2009; Figures 2D, 3B).

Exploring STDP expression with specific pharmacological targeting of EAAT2 glutamate uptake uncovers that together with its control over plasticity magnitude, EAAT2 tightly regulates the temporal window for plasticity induction in the rat dorsolateral striatum (Valtcheva and Venance, 2016; Figures 2C, 3C; Table 1). Indeed, specific pharmacological blockade of EAAT2 (with DHK or WAY-213,613) during the STDP induction protocol results in a broadening of the permissive window for plasticity expression at corticostriatal synapses. Inhibition of EAAT2 promotes the expression of spiketiming-dependent LTD (t-LTD) or spike-timing-dependent LTP (t-LTP) at temporal intervals, where no plasticity is observed under control conditions (beyond $\Delta \mathrm{t}_{\text {STDP }}= \pm 30 \mathrm{~ms}$ for $1 \mathrm{~Hz}$ pairings). Upon EAAT2 inhibition, plasticity expression does not follow STDP rule, as a non-timing-dependent LTP can be triggered by uncorrelated events (randomized pre-post and post-pre pairings) or even unpaired activity (postsynaptic activation alone). EAAT2 inhibition reveals an overlap between non-timing-dependent LTP and LTD triggered by the recruitment of GABAergic networks at a narrow temporal window $\left(-70<\Delta\right.$ t $_{\text {STDP }}<+70 \mathrm{~ms}$; Valtcheva and Venance, 2016). On the contrary, overexpression of EAAT2 following chronic ceftriaxone treatment of rats results in a lack of STDP at corticostriatal synapses (Valtcheva and Venance, 2016; Figures 2E, 3D). Therefore, EAAT2 control the expression of spike-timing-based plasticity but also acts as a selector for Hebbian vs. non-Hebbian plasticity.

\section{HOW EAATS CONTROL LONG-TERM PLASTICITY}

EAATs regulate the expression of both rate- and spiketiming-based long-term plasticity by several mechanisms. EAATs control the extent of activation of receptors present in synaptic and peri-/extrasynaptic compartments, or on neighboring neurons, by controlling the temporal and spatial profile of the glutamate transient (Tong and Jahr, 1994; Brasnjo and Otis, 2001; Clark and Cull-Candy, 2002; Dzubay and Otis, 2002; Reichelt and Knöpfel, 2002; Attwell and Gibb, 2005; Tzingounis and Wadiche, 2007; Chalifoux and Carter, 2011). Synaptically released glutamate diffuses out of the synaptic cleft and binds to NMDARs and mGluRs in the peri- or extrasynaptic membrane or at neighboring synapses (Kullmann et al., 1996; Barbour and Häusser, 1997; Scanziani et al., 1997; Kullmann and Asztely, 1998; Szapiro and Barbour, 2007). The extent of such extrasynaptic actions is regulated by the high-affinity glutamate uptake operated mainly by EAAT2 (Asztely et al., 1997; Bergles and Jahr, 1997; Min et al., 1998; Rusakov and Kullmann, 1998; Lehre and Rusakov, 2002; Zheng et al., 2008). EAAT2 rapidly reduces the free concentration of glutamate but part of the content of the exocytosis of presynaptic vesicles binds to glutamatergic receptors situated in the immediate perisynaptic space (Rusakov and Kullmann, 1998; Zheng et al., 2008). Moreover, sustained episodes of high-frequency presynaptic activity delay glutamate clearance by astrocytes and allow prolonged activation of NMDARs (Armbruster et al., 2016). Finally, diffusion of EAAT2 on the astrocytic membrane is crucial for the glutamate buffering function of EAAT2, thus 


\section{EAAT inhibition / deletion}

A

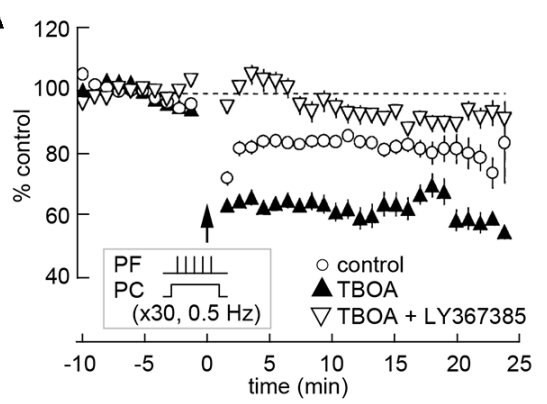

B

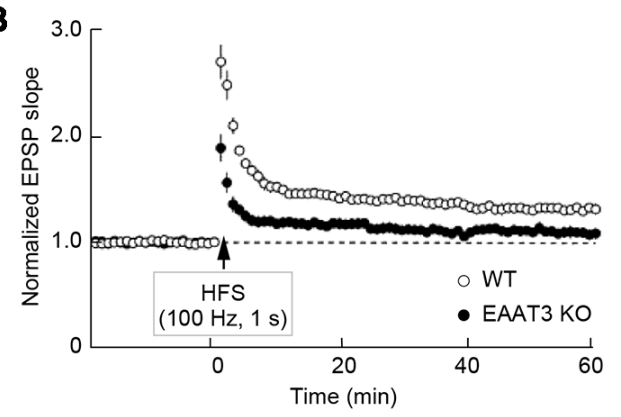

C2
C1

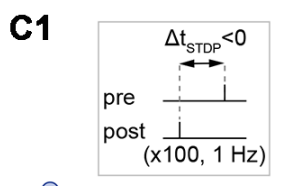

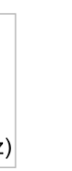

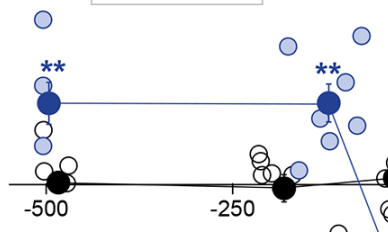

$\bigcirc \bigcirc$
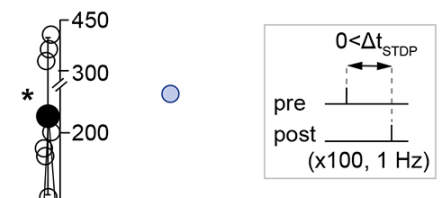

$(x 100,1 \mathrm{~Hz})$

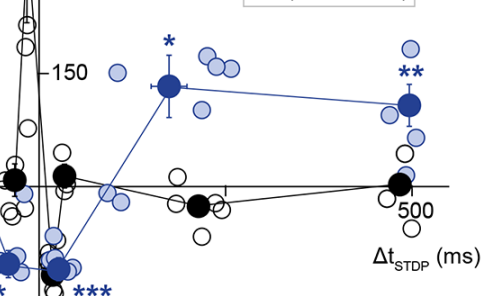

O Control

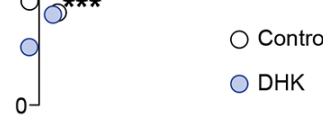

Normalized EPSC (\%)
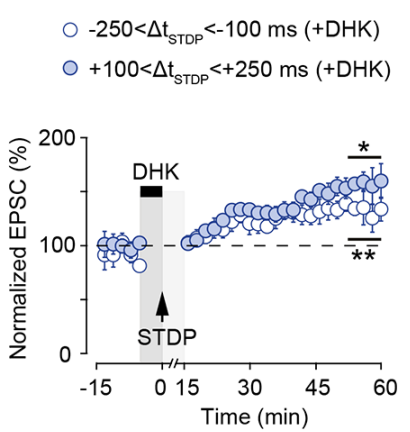

DHK

EAAT2 overexpression

D

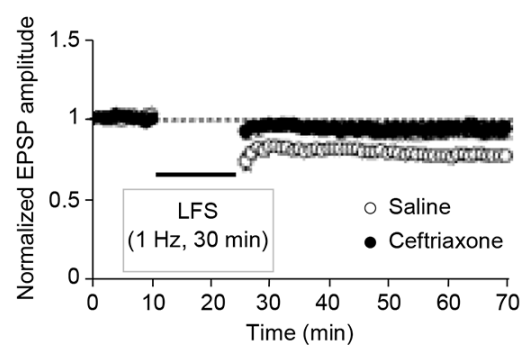

E

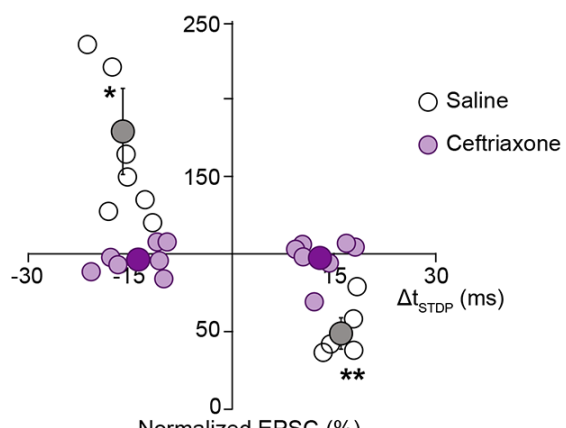

Normalized EPSC (\%)

FIGURE 2 | Modulation of long-term synaptic plasticity by EAATs. (A) Pharmacological inhibition of EAATs by the broad-spectrum non-transportable blocker threo- $\beta$-benzyloxyaspartic acid (TBOA) increases the magnitude of long-term depression (LTD) in cerebellar Purkinje cells, triggered by high frequency stimulation (HFS) of the parallel fibers (five pulses at $100 \mathrm{~Hz}$ ) paired with Purkinje cell depolarization ( $0 \mathrm{mV}$ for $50 \mathrm{~ms}$ ) repeated at $0.5 \mathrm{~Hz}$ for $1 \mathrm{~min}$. This LTD is mGluR1-dependent since it is inhibited by LY367385. Adapted with permission from Brasnjo and Otis (2001). (B) Genetic deletion of EAAT2 decreases the amplitude of HFS-induced long-term potentiation (LTP) in the stratum radiatum region of the hippocampus. Adapted with permission from Katagiri et al. (2001). (C) Specific pharmacological blockade of EAAT2 with dihydrokainic acid (DHK) results in a broadening of the permissive window for spike-timing dependent plasticity (STDP) expression at corticostriatal synapses. Inhibition of EAAT2 results in t-LTD or t-LTP at temporal intervals where no plasticity is observed under control conditions (beyond $\Delta \mathrm{t}_{\mathrm{STDP}}= \pm 30 \mathrm{~ms}$ ). (C1) Time window $\left(\Delta \mathrm{t}_{\mathrm{STDP}}\right.$ ) for long-term synaptic strength for post-pre and pre-post pairings. (C2) Averaged time-course of experiments with transient blockade of EAAT2 with bath-application of DHK for post-pre and pre-post pairings beyond $\Delta \mathrm{t}_{\mathrm{STDP}}= \pm 100 \mathrm{~ms}$. Adapted with permission from Valtcheva and Venance (2016). (D) Overexpression of EAAT2 by chronic ceftriaxone treatment prevents the expression of low frequency stimulation (LFS)-induced LTD at the hippocampal mossy fibers-CA3 synapse. Adapted with permission from Omrani et al. (2009). (E) STDP time window ( $\Delta \mathrm{t}_{\mathrm{STDP}}$ ) for long-term synaptic strength for post-pre and pre-post pairings showing that overexpression of EAAT2 by chronic ceftriaxone treatment prevents the expression of STDP at corticostriatal synapses. Adapted with permission from Valtcheva and Venance (2016). ${ }^{*} p<0.05 ;{ }^{* *} p<0.01 ; * * *<0.001$ 

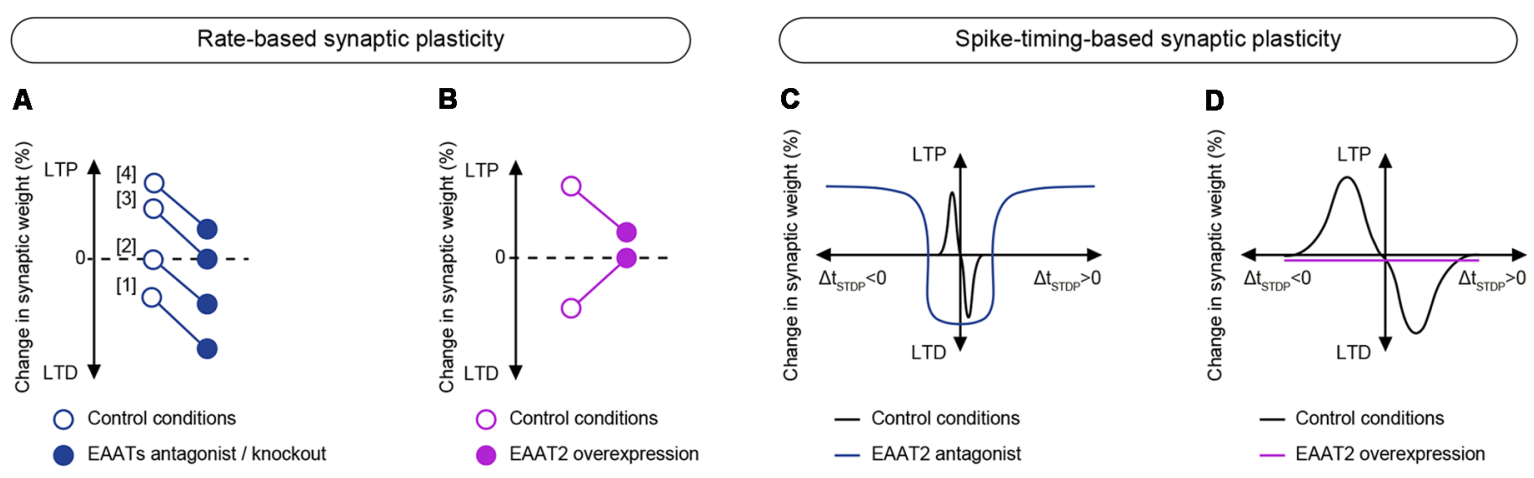

FIGURE 3 | Effects of EAATs modulation on long-term plasticity. (A,B) Effects of EAATs regulation on rate-based plasticity. (A) Downregulation of EAATs by pharmacological inhibition or genetic knock-out (closed circles) results in a lower threshold for LTD induction and a higher threshold for LTP induction using rate-based plasticity paradigms compared to control conditions (open circles). Pharmacological inhibition of EAATs: (1) increases LTD magnitude (Brasnjo and Otis, 2001); (2) promotes LTD (Massey et al., 2004; Wong et al., 2007); (3) prevents LTP induction (Wang et al., 2006). Genetic knock-out of EAATs; and (4) decreases LTP amplitude (Katagiri et al., 2001; Scimemi et al., 2009). (B) Upregulation of EAATs by chronic ceftriaxone treatment (closed circles) prevents the expression of LFS-induced LTD and decreases the amplitude of HFS-induced LTP compared to control conditions (open circles; Omrani et al., 2009). (C,D) Effects of EAATs regulation on spike-timing-based plasticity. (C) Downregulation of EAAT2 by pharmacological inhibition with DHK results in a broadening of the permissive window $\left(\Delta t_{\text {STDP }}\right)$ for plasticity expression (Valtcheva and Venance, 2016). (D) Upregulation of EAATs by chronic ceftriaxone treatment prevents the expression of STDP (Valtcheva and Venance, 2016).

allowing the transporter to relocate between synaptic and peri-/extrasynaptic sites (Murphy-Royal et al., 2015). There is a critical role of glutamate diffusion in determining the balance of receptor activation and EAATs control the degree to which receptors located outside the cleft are activated following each release event (Bergles et al., 1997; Min et al., 1998; Zheng et al., 2008).

\section{EAATs Control the Activation of Receptors Involved in Long-Term Plasticity}

Up- or down-regulation of glutamate uptake can have a profound effect on plasticity expression or magnitude. Increase in EAATs density would increase the buffering capacity for glutamate and decrease glutamate receptor stimulation as EAATs compete for the extracellular glutamate with NMDARs and mGluRs located in the peri- or extrasynaptic space (Bergles et al., 2002; Tzingounis and Wadiche, 2007; Figure 1). Increasing glutamate clearance can also reduce synaptic receptor activation (Min et al., 1998). In contrast, downregulation of EAATs should allow extended binding of glutamate to its receptors (Figure 1)

Up-regulation of EAAT2, with ceftriaxone (Rothstein et al., 2005), prevents LFS-LTD and decreases the magnitude of HFS-LTP at the hippocampal mossy fibers-CA3 synapse (Omrani et al., 2009; Figures 2D, 3C). The effect on LFS-LTD can be explained by the enhanced glutamate clearance resulting from EAAT2 up-regulation, thus limiting the activation of perisynaptic mGluRs which are responsible for LFS-LTD induction at the mossy fibers-CA3 synapse (Kobayashi et al., 1996; Yokoi et al., 1996). Indeed, bath-applied DHK during LFS rescues LTD in ceftriaxone-treated animals, by promoting glutamate accumulation and mGluRs activation (Omrani et al., 2009). Likewise, reduced glutamate access to presynaptic kainate receptors, which mediates HFS-LTP at the mossy the fibers-CA3 synapse (Schmitz et al., 2003) might account for the reduction in HFS-LTP magnitude. A similar mechanism is likely involved in the loss of striatal t-LTD and t-LTP expression after EAAT2 up-regulation with ceftriaxone treatment (Valtcheva and Venance, 2016; Figures 2E, 3D). At corticostriatal synapses in the dorsolateral striatum, t-LTD is mGluR-mediated and t-LTP depends on NMDARs (Fino et al., 2010; Evans et al., 2012), and these receptors are located within but also outside the synaptic cleft (Baude et al., 1993; Paoletti et al., 2013). Therefore, EAAT2 overexpression may limit the activation of receptors responsible for STDP induction and impair the detection of correlated synaptic activity.

EAATs inhibition by TBOA increases the magnitude of associative mGluR-dependent LTD at cerebellar parallel fiberPurkinje cell synapse by enhancing mGluRs transmission (Brasnjo and Otis, 2001; Figures 2A, 3A). Specific pharmacological blockade of EAAT2 with intrathecal infusion of DHK in the spinal dorsal horn decreases HFS-LTP magnitude at lower doses of DHK and precludes LTP expression at higher doses (Wang et al., 2006; Figure 3A). LTP of unmyelinated C-fibers onto spinal dorsal horn neurons synapse relies on NMDARs activation (Randi ć et al., 1993). Therefore, continuous EAAT2 blockade (via intrathecal DHK infusion) and subsequent glutamate accumulation may result in excessive NMDAR stimulation, neuronal depolarization and subsequent increase in intracellular $\mathrm{Ca}^{2+}$ concentration, which would hinder further LTP induction. Similarly, genetic deletion of either astrocytic EAAT2 (Katagiri et al., 2001) or neuronal EAAT3 (Scimemi et al., 2009) impairs HFS-LTP in the hippocampus, most likely due to the chronic activation of NMDARs (Figure 3A). In knock-out mice for either EAAT2 or EAAT3 (Katagiri et al., 2001), glutamatergic transmission is increased, which may lead to enhanced stimulation of NMDARs, therefore precluding the ability of synapses to further potentiate. 


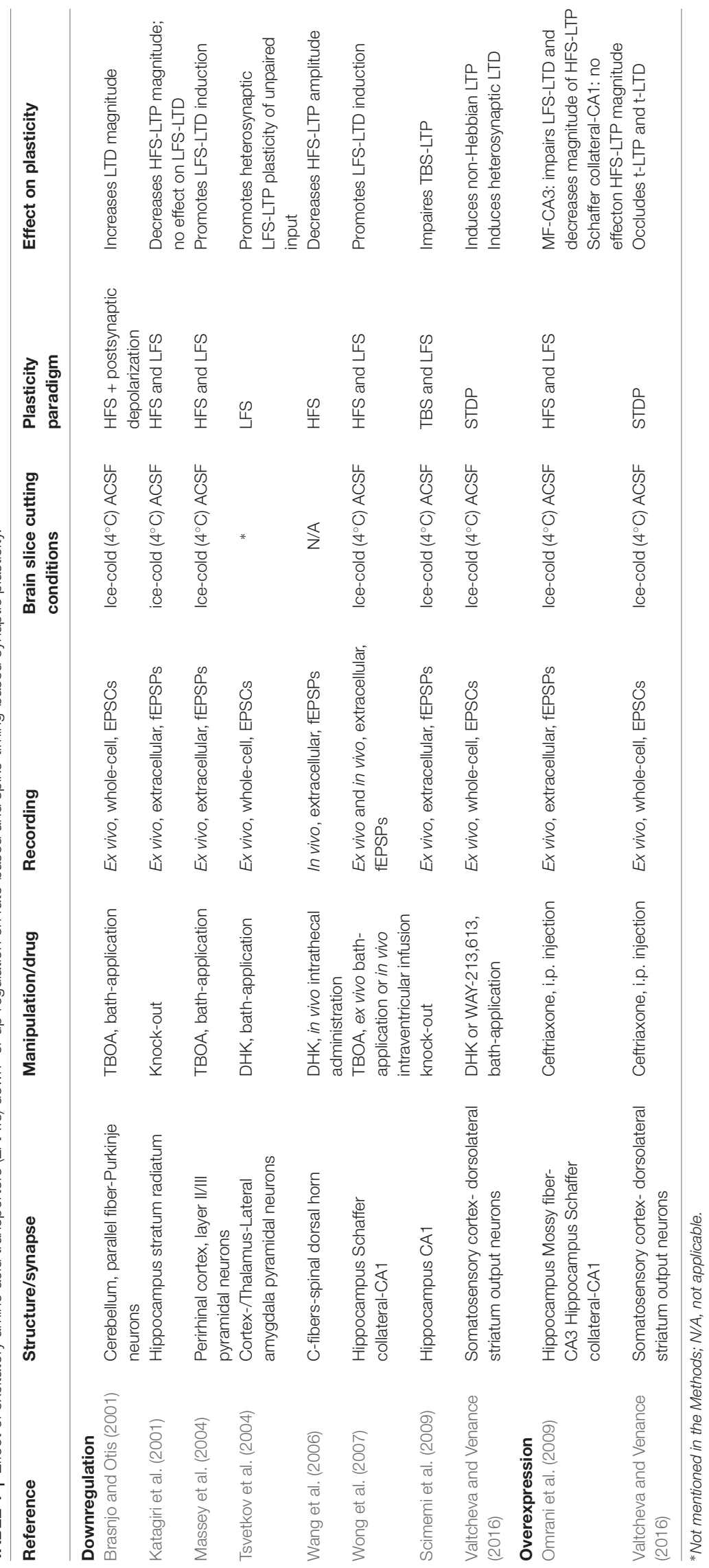


Distinct natural expression patterns of EAATs also affect plasticity expression in different regions. Indeed, Purkinje cells in the cerebellar vermis express lower levels of EAAT4 and exhibit mGluR-dependent LFS-LTD at the parallel fiberPurkinje cell synapse. In contrast, LFS-LTD is absent in the cerebellar flocculus where EAAT4 is highly expressed, which might decrease the extent of mGluRs recruitment during HFS (Wadiche and Jahr, 2005).

\section{EAATs Prevent the Expression of Aberrant Plasticity}

EAATs control the extent of glutamate spillover and the access of glutamate to receptors located at the peri- and extrasynaptic sites (Figure 1). Although EAATs are not overwhelmed by physiological activity, a total synaptic isolation is not reached (Asztely et al., 1997; Diamond and Jahr, 1997, 2000). Receptors that are typically not recruited by glutamate release under afferent stimulation in control conditions, can become key actors of long-term plasticity when glutamate uptake is altered (Tzingounis and Wadiche, 2007). Therefore, physiological or pathological down-regulation of EAATs has a permissive role for the expression of different forms of long-term plasticity (Massey et al., 2004; Wong et al., 2007; Aida et al., 2015; Valtcheva and Venance, 2016). EAATs prevent the expression of aberrant plasticity that is absent in physiological conditions but can be revealed when EAATs are blocked. Both rate(Massey et al., 2004; Wong et al., 2007) and spike-timingbased (Valtcheva and Venance, 2016) paradigms which fail to induce changes in synaptic strength in control conditions in vivo and ex vivo, can promote long-term plasticity when glutamate uptake is impaired.

Pharmacological inhibition of all EAAT subtypes by TBOA in the perirhinal cortex (Massey et al., 2004) and in the CA1 region of the hippocampus (Wong et al., 2007) has a permissive role for the expression of in vivo and ex vivo LFS-LTD, mediated by NMDARs containing the GluN2Bsubunit (Figure 3A). In the dorsolateral striatum, specific EAAT2 inhibition by DHK (or WAY-213,613) disrupts the temporal contingency between pre- and postsynaptic activity, which is required for STDP expression (Valtcheva and Venance, 2016; Figures 2C, 3C). The sharp sensitivity to the timing of synaptic inputs of striatal STDP is erased in conditions of EAAT2 blockade when DHK (or WAY$213,613)$ is applied exclusively during the STDP protocol. This promotes the expression of a non-timing-dependent LTP mediated by GluN2B-NMDARs which is can also be induced by uncorrelated pre- and postsynaptic events. This nontiming-dependent LTP is absent in control conditions when EAAT2 activity is intact.

\section{EAATs Ensure Synaptic Independence}

Astrocytic EAAT2 is of crucial importance for limiting glutamate spillover to neighboring synapses, and therefore tightly controlling both cooperation and synaptic independence (Arnth-Jensen et al., 2002; Huang et al., 2004; Scimemi et al., 2004; Attwell and Gibb, 2005; Tzingounis and Wadiche, 2007; Figure 1). High-affinity NMDARs and mGluRs, located on peri- or extrasynaptic sites (Baude et al., 1993; Paoletti et al., 2013), or on neighboring neurons, mediate most of the glutamatergic spillover responses and their activation is limited by active astrocytic glutamate uptake (Kullmann and Asztely, 1998; Diamond and Jahr, 2000; Huang and Bergles, 2004; Coddington et al., 2013). Therefore, inhibition of EAAT2 favors synaptic crosstalk by the recruitment of neighboring neurons (Huang et al., 2004), or via the loss of specificity of afferent inputs (ArnthJensen et al., 2002; Scimemi et al., 2004).

EAAT2 blockade results in heterosynaptic LTP in the lateral amygdala (Tsvetkov et al., 2004). LTP at both cortical and thalamic synapses onto pyramidal cells in the lateral amygdala depends on NMDAR activation (Huang and Kandel, 1998; Bauer et al., 2002; Tsvetkov et al., 2002, 2004). Specific pharmacological blockade of EAAT2 with DHK leads to the loss of input specificity in the lateral amygdala, most likely by promoting intersynaptic crosstalk between cortical and thalamic inputs onto pyramidal cells (Tsvetkov et al., 2004). Glutamate spillover may also recruit neighboring interneurons and their activation can impact long-term plasticity expression of principal cells. Indeed, specific blockade of EAAT2 with DHK results in an increased inhibitory drive from GABAergic microcircuits in the striatum (Valtcheva and Venance, 2016). Suprathreshold activation of GABAergic interneurons by cortical stimulation masks the expression of non-timing-dependent LTP of striatal output neurons. In these conditions, enhanced inhibitory transmission promotes the expression of GABA-dependent LTD, instead of postsynaptic NMDAR-mediated LTP, at a narrow temporal window. As a result, postsynaptic NMDAR-mediated LTP is expressed only at a larger temporal window, when the cortical stimulation occurs far from the postsynaptic spike and thus the strong inhibitory drive does not interfere with postsynaptic LTP expression (Valtcheva and Venance, 2016; Figures 2C, 3C).

\section{EAATs Set the Balance Between LTP and LTD}

Interestingly, in many cases of rate-based synaptic plasticity EAATs downregulation by either genetic or pharmacological manipulations leads to a reduction of LTP magnitude or occludes its expression (Katagiri et al., 2001; Wang et al., 2006; Scimemi et al., 2009) and promotes LTD (Brasnjo and Otis, 2001; Massey et al., 2004; Wong et al., 2007; Figure 3A). Therefore, blockade of glutamate transport may alter the balance between LTP and LTD (Katagiri et al., 2001; Scimemi et al., 2009) by reducing LTP magnitude and promoting LTD. Imposing a bias towards synaptic depression in conditions when EAAT activity is downregulated, may result from a shift in the modification threshold for plasticity induction (Cooper and Bear, 2012) by lowering LTD threshold and increasing LTP threshold (Figure 3A). When synaptic glutamate spillover is chronically enhanced and levels of ambient glutamate are thus increased, LTP induction can also be damped by plasticity saturation (Katagiri et al., 2001; Scimemi et al., 2009). In contrast, promoting glutamate spillover can facilitate glutamate access to extrasynaptic glutamate receptors and thus lower LTD threshold (Massey et al., 2004; Wong et al., 2007). It is worthy of note 
that increasing the frequency of afferent stimulation in control conditions can induce LTD (Figure 3), thus mimicking the effects of EAATs inhibition (Massey et al., 2004). A subtle balance between LTP and LTD should be of crucial importance for optimal memory storage in neural networks and altering glutamate uptake can have profound consequences for learning and memory.

In contrast to the effects triggered by inhibition of glutamate uptake, EAAT2 overexpression with ceftriaxone tends to suppress plasticity expression by altering both LTP and LTD (Omrani et al., 2009; Valtcheva and Venance, 2016; Figures 3B,D). It would be appealing to explore if increasing the frequency of afferent activation could overcome enhanced glutamate uptake by promoting an increased glutamate spillover and, therefore, restoring plasticity.

\section{CONSEQUENCES OF EAATS ALTERATION ON BEHAVIOR}

Because EAAT activity controls synaptic plasticity, glutamate uptake is expected to play an essential role in learning and shaping behavior. Although making a causal direct link between molecular impairment with behavioral changes is challenging, we review in this chapter studies correlating the effect of EAATs alterations to behavioral outputs.

In vivo chronic blockade of EAAT2 by DHK infusion in the central nucleus of the amygdala induces anxiety (John et al., 2015). This anxiogenic effect could arise from disrupted input specificity in amygdala networks, processing both fear and reward cues, due to enhanced glutamate spillover (Janak and Tye, 2015). Similarly, specific blockade of EAAT2 leads to the loss of specificity of cortical and thalamic inputs onto pyramidal cells in the lateral amygdala, resulting in heterosynaptic LTP of the unpaired input (cortical or thalamic; Tsvetkov et al., 2004). Fear conditioning has been shown to strengthen cortical inputs to the lateral amygdala (Tsvetkov et al., 2002). Therefore heterosynaptic LTP of these inputs following EAAT2 downregulation might impair fear memory formation. The proper functioning of other types of glutamate transporters might also be involved in fear memory formation as mice lacking EAAT3 exhibit decreased freezing behavior following fear conditioning (Wang et al., 2014).

EAATs impairment has consequences on social interactions, reward processing and motivation. EAAT1 knock-out mice exhibit poor nesting behavior and decreased sociability measured by the time spent sniffing an unfamiliar mouse during free social interaction (Karlsson et al., 2009). EAATs blockade in the basolateral amygdala decreases social interactions (Lee et al., 2007). In addition, blocking EAAT2 by in vivo DHK infusion in the ventral tegmental area, decreases response to electrical self-stimulation in the medial forebrain bundle (Herberg and Rose, 1990), suggesting that astrocytic glutamate uptake also controls brain reward circuitry. Astrocytic ablation by the gliotoxin L-alpha-aminoadipic acid in the prelimbic part of the prefrontal cortex results in both decreased motivation and increased anxiety (Banasr and Duman, 2008). It is important to note, however, that bulk ablation of astrocytes results not only in decreased levels of astrocytic EAAT2 but it can also impair other astrocytic functions such as gliotransmission and metabolic support, and may result in structural changes of synapses. In vivo EAAT2 blockade by DHK in the infralimbic part of the prefrontal cortex (John et al., 2012) or intracerebroventricular infusion of DHK (Bechtholt-Gompf et al., 2010) results in depressive-like behaviors and anhedonia, which are translated by a reduction in motivation and reward-seeking. Interestingly, these effects are prevented by EAAT2 up-regulation following ceftriaxone treatment (Mineur et al., 2007).

In contrast, in vivo infusion of $\mathrm{DHK}$ in the infralimbic part of the prefrontal cortex reduced despair and anxiety (GasullCamós et al., 2017). These effects were not observed when DHK was infused in the prelimbic part of the prefrontal cortex. The effect of increased glutamatergic tone, following DHK infusion, might either stimulate local serotoninergic release or increase the transmission of prefrontal inputs to brainstem serotoninergic neurons and subsequently trigger serotonin release in the infralimbic cortex, thus suppressing anxiety. The molecular pathways and synaptic plasticity mechanisms underlying these phenotypes remain to be determined.

The effects of EAAT2 overexpression on hippocampal learning are complex. EAAT2 overexpression by ceftriaxone impairs LTD and reduces LTP magnitude at the mossy fiber-CA3 synapses (Omrani et al., 2009). Ceftriaxone-treated rats or mice display impaired novel object recognition (Matos-Ocasio et al., 2014; Tian et al., 2019), whereas ceftriaxone administration in mice has no effect on spatial memory (Karaman et al., 2013). Inhibition of EAATs with TBOA facilitates hippocampal LTD induction in vivo and ex vivo, and disrupts spatial memory retrieval in mice (Wong et al., 2007). CA1 hippocampal LTP is also impaired in knock-out mice for either EAAT2 or EAAT3 (Katagiri et al., 2001; Scimemi et al., 2009), although spatial orientation in the Morris water maze when tested in EAAT3deficient mice remains unaffected (Peghini et al., 1997).

In vivo intrathecal administration of the specific EAAT2 inhibitor DHK impairs LTP of evoked field potentials at C-fiber in the spinal dorsal horn, induced by tetanic stimulation of the sciatic nerve (Wang et al., 2006), and induces spontaneous nociceptive behaviors (Liaw et al., 2005). In addition, an intrathecal infusion of the broad-band EAAT inhibitor TBOA leads to hypersensitivity in response to thermal and mechanical stimuli (Liaw et al., 2005).

Variations in glutamate uptake also affect locomotion. EAAT3 deficient mice display normal motor coordination assessed by rotarod task but a decreased spontaneous locomotion in an open field (Peghini et al., 1997). In contrast, an increased spontaneous locomotion is observed in ceftriaxone-treated rats (Bellesi et al., 2012). Knock-out mice for EAAT1 exhibit motor discoordination in rotarod task (Watase et al., 1998), noveltyinduced locomotor hyperactivity measured as an increase in distance traveled during exposure to an open field, and impaired sensory-motor gating translated by reduced acoustic startle response (Karlsson et al., 2008, 2009).

Finally, an inducible astrocytic EAAT2 deletion leads to pathological repetitive behaviors and glutamatergic overactivity (used as a proxy for LTP) in the dorsal striatum 
(Aida et al., 2015). This is the first study aiming at linking behavior with the effect of EAAT2 downregulation on synaptic plasticity. This spurious plasticity in EAAT2 knock-out mice is likely induced by excessive glutamate spillover as it is dependent on extrasynaptic NMDARs activation. Moreover, the repetitive behavior was diminished by memantine, an extrasynaptic NMDAR antagonist (Aida et al., 2015).

\section{PHYSIOLOGICAL VARIATION OF EAATS LEVELS}

\section{Variations in Glial Coverage and EAATs Expression Across Synapses}

Perisynaptic astrocytic processes expressing EAAT1 and EAAT2 are found in all brain regions but the degree of astrocytic coverage is region-specific and the proportion of synapses surrounded by processes can be highly variable within the same structure (Bernardinelli et al., 2014a; Medvedev et al., 2014; Heller and Rusakov, 2015; Khakh and Sofroniew, 2015; Gavrilov et al., 2018). Astrocytic enwrapment of synapses controls the spatial distribution of EAATs and thus their efficiency to uptake glutamate (Oliet et al., 2001; Boudaba et al., 2003; Genoud et al., 2006).

An example of non-uniform distribution of perisynaptic astrocytic processes within the same structure is found in the cerebellum and hippocampus. Climbing fiber-Purkinje cell synapse is extensively enwrapped by astrocytic processes, whereas mossy fiber-granule cell layer synapses (mainly Golgi cells) in the cerebellar vermis are moderately surrounded by astrocytic processes (Xu-Friedman et al., 2001; Xu-Friedman and Regehr, 2003). Mossy fiber-granule cell layer synapses display both rate-based plasticity and STDP depending on the input frequency (D'Errico et al., 2009; Sgritta et al., 2017). Rate-dependent LTD and LTP are induced with LFS $(\leq 1 \mathrm{~Hz})$ and HFS $(>50 \mathrm{~Hz})$, respectively, while the frequency range for STDP induction is restricted at the mid-frequency range (6-10 Hz; D'Errico et al., 2009; Sgritta et al., 2017). In the hippocampus, CA3 synapses have lower glial coverage compared with CA1 synapses (Derouiche and Frotscher, 1991; Rollenhagen et al., 2007). Interestingly, upregulation of EAAT2 by ceftriaxone prevents LFS-LTP at mossy fiber-CA3 synapses but not at Schaffer collateral-CA1 (Omrani et al., 2009). LTP at CA3 synapses is mediated by presynaptic kainate receptors (Schmitz et al., 2003), which are particularly sensitive to synaptic glutamate levels (Min et al., 1998), whereas LTP at Schaffer collateral-CA1 depends on postsynaptic NMDARs (Nicoll and Malenka, 1995). Therefore, increasing glutamate uptake via EAAT2 upregulation selectively alters HFS-LTP at mossy fiber-CA3 synapses (Omrani et al., 2009).

EAAT density can also differ across similar synapses within the same structure. Purkinje cells in the flocculus express higher levels of EAAT4 than Purkinje cells in the vermis and the regional differences in neuronal transporter density affect the expression of parallel fiber-Purkinje cell LFS-LTD (Wadiche and Jahr, 2005). Interestingly, the rules for induction of Purkinje cell LTD also differ between these two regions. In the vermis, both
LFS of parallel fibers and input-timing-dependent stimulation of parallel and climbing fibers result in LFS-LTD and t-LTD, respectively (Wadiche and Jahr, 2005; Safo and Regehr, 2008; Suvrathan et al., 2016). In contrast, Purkinje cells of the flocculus exhibit t-LTD but not LFS-LTD (Wadiche and Jahr, 2005; Suvrathan et al., 2016), suggesting that high EAATs levels might disfavor the expression of rate-based plasticity. Lower EAAT4 expression in the vermis may allow both rate-based and spike-timing-based LTD at Purkinje cells, whereas higher levels of EAAT4 in the flocculus may prevent LFS-LTD, but allow $\mathrm{t}$-LTD to occur at larger temporal intervals $\left(\Delta \mathrm{t}_{\mathrm{STDP}}=120 \mathrm{~ms}\right.$; Suvrathan et al., 2016). This may favor the association of non-coincident inputs occurring with a longer delay than the decay time of transporter currents resulting from parallel fiber stimulation (Wadiche and Jahr, 2005; Suvrathan et al., 2016).

\section{Plasticity of Glial Coverage and EAATs Expression}

Astrocytic enwrapment of neurons controlling glutamate clearance exhibits structural plasticity in response to neuronal activity and can be modulated by experience. The density of astrocytic processes is increased in the layer II/III of the visual cortex of rats which were reared in an enriched environment with new toys and increased social interactions (Jones et al., 1996). Another type of sensory experience such as prolonged whisker stimulation increases the astrocytic enwrapment of synapses and EAAT2 expression in the sensory cortex (Genoud et al., 2006). Interestingly, following whisker stimulation, the motility of astrocytic endfeets is increased specifically in the corresponding whisker barrel while stimulation of the surrounding whisker fails to induce such effect (Bernardinelli et al., 2014b). Negative experience like stress alters hippocampal EAAT2 expression with a biphasic profile: acute stress, via tail shock, downregulates EAAT2 levels (Yang et al., 2005), whereas chronic restraint stress upregulates EAAT2 (Reagan et al., 2004). Different learning paradigms can also trigger structural plasticity of astrocytes and EAATs expression. Motor-skill learning induces glial hypertrophy in the molecular layer of cerebellum leading to a greater volume of glia per Purkinje cell, possibly limiting glutamate spillover (Anderson et al., 1994). Similarly, voluntary free exercise on a running wheel for 3 weeks results in increased ramification and more complex morphology of astrocytic processes in the globus pallidus of mice. These changes are correlated with sustained physical exercise since they disappear after a resting period of additional 3 weeks (Tatsumi et al., 2016). Contextual fear conditioning increases the rate of glutamate uptake and EAAT3 membrane expression in the hippocampal CA1 region (Levenson et al., 2002). This suggests that increased glial ensheathment of synapses and upregulation of glutamate uptake may be especially important for counterbalancing the increased synaptic efficacy and maintaining the synaptic strength following experience-dependent potentiation. Indeed, hippocampal LTP is associated with an increase in the astrocytic coverage of pre- and postsynaptic elements (Lushnikova et al., 2009), an increase in the EAAT3- and EAAT2-dependent glutamate 
uptake during the early and late phase of LTP, respectively, and EAAT3 translocation from the cytosol to the plasma membrane (Diamond et al., 1998; Lüscher et al., 1998; Levenson et al., 2002; Kawamura et al., 2004; Pita-Almenar et al., 2005, 2006). In addition, LTP-induced astrocytic group-I mGluR-dependent potentiation of EAAT2 glutamate uptake, as well as membrane insertion of EAAT1, has been reported (Shen and Linden, 2005; Devaraju et al., 2013).

Decrease in the glial enwrapment of synapses onto oxytocinergic neurons in the hypothalamus of female rats occurs with the transition to motherhood during the lactation period and these changes are reversed in post-lactating animals (Theodosis and Poulain, 1993). This results in an increase in the tonic glutamate concentration likely due to altered glutamate clearance (Oliet et al., 2001). This, in turn, decreases the probability of glutamate release by activation of presynaptic type-III mGluRs mediated by glutamate spillover (Oliet et al., 2001). Similar retraction of astrocytic endfeet occurs with chronic dehydration when rats drink hypertonic saline for several days (Perlmutter et al., 1985; Chapman et al., 1986), which results in a decreased expression of EAAT2 and activation of presynaptic type-III mGluRs (Boudaba et al., 2003). Increased tonic glutamate concentration activates postsynaptic GluN2B-NMDARs and increases neuronal excitability and firing frequency of hypothalamic neurons (Fleming et al., 2011; Naskar and Stern, 2014). Interestingly, both HFS-LTP and LFS-LTD induced in the hypothalamus of female rats are NMDAR-dependent (Panatier et al., 2006a) and, therefore, might be sensitive to changes in glutamate uptake triggered by astrocytic structural plasticity. The switch in the threshold for plasticity induction in lactating rats is attributed to a decreased GluN2B-NMDARs activation caused by a deficiency in D-serine signaling (Panatier et al., 2006b). An alternative mechanism could be that the retraction of astrocytes and increased glutamate uptake may serve as a high-pass filter, increasing HFS-LTP threshold by prioritizing high-frequency afferent inputs.

Physiological fluctuations in the glial coverage of neurons can occur in a cyclic manner. Indeed, in the arcuate hypothalamic nucleus, the density of astrocyte cell bodies and processes revealed an increased on the afternoon of proestrus and on the morning of estrus compared to other phases of the oestrous cycle. This structural plasticity is dependent on estradiol and absent in ovariectomized rats (Garcia-Segura et al., 1994). Neurons in the suprachiasmatic hypothalamic nucleus undergo rhythmic ultrastructural rearrangements in their astrocytic coverage over the circadian cycle (Lavialle et al., 2001; Becquet et al., 2008). Importantly, this structural plasticity is synapse-specific. At nighttime, the glial coverage of neurons expressing the vasoactive intestinal peptide increases, whereas the glial coverage of arginine vasopressin-expressing neurons decreases (Becquet et al., 2008). Glutamate uptake is crucial in the regulation of neuronal circadian oscillations (Brancaccio et al., 2017). Sleep deprivation induces upregulation of EAAT1 and increased glial coverage in the prefrontal cortex (Bellesi et al., 2015). In contrast, sleep deprivation has a synapse-specific effect in the lateral hypothalamus as it decreases EAAT2 expression around wake-promoting orexin neurons, while it increases EAAT2 around sleep-promoting melanin-concentrating hormone neurons (Briggs et al., 2018). In conclusion, EAATs exert a tight control of endogenous rhythms by regulating the degree of coordination between neurons and most likely by setting the threshold for synaptic plasticity induction.

It should be taken into consideration that some experimental conditions can affect glial coverage and thus synaptic plasticity. Indeed, acute brain slice preparation and incubation methods (Table 1) may alter the ultrastructure of the neuropil (Bourne et al., 2007; Bourne and Harris, 2012; Harris and Bourne, 2012) and likely the morphology of the fine astrocytic processes, which in turn could affect long-term synaptic plasticity expression. Exposure to ice-cold artificial cerebrospinal fluid (ACSF) has been reported to induce synaptogenesis and increase in spine density in acute hippocampal slices, which can be prevented if slices are prepared at room temperature (Bourne et al., 2007; Bourne and Harris, 2012). Similarly, incubation of acute hippocampal slices in submerged chamber results in a loss or retraction of astrocytic process but can be prevented if slices are incubated in an interface chamber (Harris and Bourne, 2012).

\section{CONCLUSIONS AND FUTURE DIRECTIONS}

Here, we reviewed studies evidencing that the subtle equilibrium between the localization and density of EAATs, together with the glial coverage of neurons, shapes not only excitatory transmission but also long-term synaptic plasticity, thus impacting on learning and memory. Interestingly, baseline GABAergic is not affected by the decrease in the astrocytic enwrapment of neurons and increased levels of ambient glutamate. Indeed, resting glutamate concentrations are not sufficient to tonically activate type-III mGluRs located on GABAergic terminals in the hypothalamus of lactating rats (Piet et al., 2004). However, the evoked inhibitory transmission is decreased when glutamatergic terminals are activated. This results in intersynaptic crosstalk and activation of presynaptic type-III mGluRs (Piet et al., 2004), or kainate receptors (Bonfardin et al., 2010) on GABAergic terminals (Figure 1). It remains to determine whether, in addition to glutamatergic synaptic plasticity (Figure 3), EAATs also control long-term synaptic plasticity of GABAergic inputs. Physiological fluctuations (Theodosis and Poulain, 1993; Garcia-Segura et al., 1994; Becquet et al., 2008; Briggs et al., 2018) and regional differences (Wadiche and Jahr, 2005) in the glial coverage of neurons and EAATs levels might thus regulate the balance between synaptic excitation and inhibition and shape excitatory and inhibitory synaptic plasticity (Vogels et al., 2013).

Increase in the glial coverage of neurons together with EAATs expression and/or proximity to presynaptic release sites would limit glutamate access to receptors involved in synaptic plasticity (Omrani et al., 2009; Valtcheva and Venance, 2016), thus increasing the threshold for plasticity induction and preventing synaptic crosstalk. Indeed, protrusion of astrocytic processes increases EAAT2 activity, without altering EAAT2 expression, and decreases the magnitude of HFS-LTP at Schaffer collateral-CA synapses (Pannasch et al., 
2014). EAAT2 might differentially control synaptic plasticity depending on the type of postsynaptic neuron. Interestingly, synaptic glutamatergic tone is higher around inhibitory neurons compared to excitatory neurons in the prefrontal cortex likely caused by a difference in the density or activity of EAAT2 (Yao et al., 2018). Therefore long-term synaptic plasticity of inhibitory neurons (Kullmann and Lamsa, 2007; Fino and Venance, 2011) might be particularly sensitive to upregulation of glutamate uptake.

Under weak glial coverage of neurons (Perlmutter et al., 1985; Theodosis and Poulain, 1993; Becquet et al., 2008), the ambient glutamatergic tone is high due to decreased glutamate uptake (Oliet et al., 2001). This may cause synapses to become less sensitive to the precise timing of pre- and post-synaptic spikes, thus inducing a switch from spike-timingto rate-coding. In this scenario, only high-frequency trains of presynaptic activity would be successful in inducing long-term synaptic plasticity. EAATs expression and their proximity to the synapse may, therefore, serve as a metaplastic mechanism to influence activity-dependent plasticity induction. Adjusting neuronal computations by EAATs may be important for synapses to adapt to different physiological demands (during sleep/wake cycle, circadian cycle, estrous cycle, lactation).

The question of whether individual neurons encode and process information by using precise spike timings, thus, working as coincidence detectors, or spike rates, thus, working as temporal integrators, has been debated (deCharms and Zador, 2000). Both mechanisms generally coexist in the same neuron. In the prefrontal cortex, depending on the synaptic inputs to layer $\mathrm{V}$ pyramidal neurons, dendrites behave either as temporal integrators or as coincident detectors (Dembrow et al., 2015). Neurons in the subthalamic nucleus operate by combining integration and coincidence detection depending on the ongoing presynaptic activity (Farries et al., 2010). Theoretical work has shown that cortical pyramidal neurons are capable of operating in a continuum between temporal integration and coincidence detection, depending on the characteristics of the synaptic inputs (Rudolph and Destexhe, 2003). Here, we hypothesize that EAATs levels, their distribution and/or astrocytic enwrapment of neurons may define if neurons operate in a rate- or spike-timingbased manner.

Future advances in in vivo two-photon imaging would allow chronic (hours or days) monitoring of astrocytic processes across different physiological states. This will make possible to image the motility of perisynaptic astrocytic endfeets around fluorescently-tagged spines of identified

\section{REFERENCES}

Aida, T., Yoshida, J., Nomura, M., Tanimura, A., Iino, Y., Soma, M., et al. (2015). Astroglial glutamate transporter deficiency increases synaptic excitability and leads to pathological repetitive behaviors in mice. Neuropsychopharmacology 40, 1569-1579. doi: 10.1038/npp.2015.26

Anderson, B. J., Li, X., Alcantara, A. A., Isaacs, K. R., Black, J. E., and Greenough, W. T. (1994). Glial hypertrophy is associated with synaptogenesis following motor-skill learning, but not with angiogenesis following exercise. Glia 80, 73-80. doi: 10.1002/glia.440110110 neuronal populations. Simultaneous monitoring of astrocytic structural rearrangements and dendritic spine remodeling of specific neuronal types will help establish a model of their dynamic relationship during learning, sensory stimulation and physiological rhythms. Perisynaptic astrocytic endfeets are highly dynamic in vivo (Bernardinelli et al., 2014b), and coupling in vivo imaging of astrocytes with in vivo whole-cell recordings of individual neurons would allow correlating astrocytic structural rearrangement and synaptic transmission and plasticity.

Genetic and pharmacological approaches have proved the crucial involvement of EAATs in synaptic plasticity. However, these tools do not provide information about the dynamics of EAATs activity at fast timescale, which may be essential for regulating the activation of synaptic and extrasynaptic glutamate receptors and thus shaping different forms of plasticity. With the rise of new tools allowing photocontrol of protein activity (Kramer et al., 2013; Durand-de Cuttoli et al., 2018) and high-speed glutamate imaging via the intensity-based glutamatesensing fluorescent reporter iGluSnFR and its fast variants (Marvin et al., 2013; Parsons et al., 2016; Helassa et al., 2018), it would be possible to manipulate EAATs activity at a millisecond timescale and monitor the time course of glutamate in coordination with pre- and postsynaptic activity. An important advance of optical methods compared to biochemical assays in measuring glutamate transport is that the time course of evoked fluorescent responses reflects transporter-mediated uptake as well as glutamate diffusion. Another crucial factor is that genetically encoded sensors can be driven under the control of a specific promoter allowing measurement of glutamate sensed at the plasma membrane of neurons, compared to glutamate responses at the astrocytic membrane measured by astrocytic transporter currents. With these powerful tools, it would be particularly interesting to explore whether EAATs activity and astrocytic coverage of synapses across different brain regions tune the sensitivity of synapses to rate- and/or STDP paradigms (Wadiche and Jahr, 2005; Suvrathan et al., 2016).

\section{AUTHOR CONTRIBUTIONS}

SV and LV wrote the review article, have edited and corrected the manuscript. SV did the figures and the table.

\section{FUNDING}

This work was supported by Université de Recherche ParisSciences-et-Lettres (PSL).

Armbruster, M., Hanson, E., and Dulla, C. G. (2016). Glutamate clearance is locally modulated by presynaptic neuronal activity in the cerebral cortex. J. Neurosci. 36, 10404-10415. doi: 10.1523/JNEUROSCI.2066-16.2016

Arnth-Jensen, N., Jabaudon, D., and Scanziani, M. (2002). Cooperation between independent hippocampal synapses is controlled by glutamate uptake. Nat. Neurosci. 5, 325-331. doi: 10.1038/nn825

Arriza, J. L., Eliasof, S., Kavanaugh, M. P., and Amara, S. G. (1997). Excitatory amino acid transporter 5, a retinal glutamate transporter coupled to a chloride conductance. Proc. Natl. Acad. Sci. U S A 94, 4155-4160. doi: 10.1073/pnas.94. 8.4155 
Arriza, J. L., Fairman, W. A., Wadiche, I., Murdoch, G. H., Kavanaugh, P., and Amara, S. G. (1994). Functional comparisons of three glutamate cloned from human motor cortex transporter. J. Neurosci. 14, 5559-5569. doi: 10.1523/JNEUROSCI.14-09-05559.1994

Asztely, F., Erdemli, G., and Kullmann, D. M. (1997). Extrasynaptic glutamate spillover in the hippocampus: dependence on temperature and the role of active glutamate uptake. Neuron 18, 281-293. doi: 10.1016/s0896-6273(00) 80268-8

Attwell, D., and Gibb, A. (2005). Neuroenergetics and the kinetic design of excitatory synapses. Nat. Rev. Neurosci. 6, 841-849. doi: 10.1038/nrn1784

Banasr, M., and Duman, R. S. (2008). Glial loss in the prefrontal cortex is sufficient to induce depressive-like behaviors. Biol. Psychiatry 64, 863-870. doi: 10.1016/j. biopsych.2008.06.008

Barbour, B., and Häusser, M. (1997). Intersynaptic diffusion of neurotransmitter. Trends Neurosci. 20, 377-384.

Baude, A., Nusser, Z., Roberts, J. D. B., Mulvihill, E., Jeffrey Mcllhinney, R. A., and Somogyi, P. (1993). The metabotropic glutamate receptor (mGluR1 $\alpha$ ) is concentrated at perisynaptic membrane of neuronal subpopulations as detected by immunogold reaction. Neuron 11, 771-787. doi: 10.1016/08966273(93)90086-7

Bauer, E. P., Schafe, G. E., and LeDoux, J. E. (2002). NMDA receptors and L-type voltage-gated calcium channels contribute to long-term potentiation and different components of fear memory formation in the lateral amygdala. J. Neurosci. 22, 5239-5249. doi: 10.1523/JNEUROSCI.22-12-05239.2002

Bechtholt-Gompf, A. J., Walther, H. V., Adams, M. A., Carlezon, W. A. Jr., Öngür, D., and Cohen, B. M. (2010). Blockade of astrocytic glutamate uptake in rats induces signs of anhedonia and impaired spatial memory. Neuropsychopharmacology 35, 2049-2059. doi: 10.1038/npp.2010.74

Becquet, D., Girardet, C., Guillaumond, F., François-Bellan, A., and Bosler, O. (2008). Ultrastructural plasticity in the rat suprachiasmatic nucleus. Glia 56, 294-305. doi: 10.1002/glia.20613

Bellesi, M., de Vivo, L., Tononi, G., and Cirelli, C. (2015). Effects of sleep and wake on astrocytes: clues from molecular and ultrastructural studies. BMC Biol. 13:66. doi: 10.1186/s12915-015-0176-7

Bellesi, M., Vyazovskiy, V. V., Tononi, G., Cirelli, C., and Conti, F. (2012). Reduction of EEG theta power and changes in motor activity in rats treated with ceftriaxone. PLoS One 7:e34139. doi: 10.1371/journal.pone.00 34139

Bellini, S., Fleming, K. E., De, M., McCauley, J. P., Petroccione, M. A., D’Brant, L. Y., et al. (2018). Neuronal glutamate transporters control dopaminergic signaling and compulsive behaviors. J. Neurosci. 38, 937-961. doi: 10.1523/JNEUROSCI.1906-17.2017

Bergles, D. E., Dzubay, J. A., and Jahr, C. E. (1997). Glutamate transporter currents in bergmann glial cells follow the time course of extrasynaptic glutamate. Proc. Natl. Acad. Sci. U S A 94, 14821-14825. doi: 10.1073/pnas.94.26.14821

Bergles, D. E., and Jahr, C. E. (1997). Synaptic activation of glutamate transporters in hippocampal astrocytes. Neuron 19, 1297-1308. doi: 10.1016/s08966273(00)80420-1

Bergles, D. E., and Jahr, C. E. (1998). Glial contribution to glutamate uptake at Schaffer collateral-commissural synapses in the hippocampus. J. Neurosci. 18, 7709-7716. doi: 10.1523/JNEUROSCI.18-19-07709.1998

Bergles, D. E., Tzingounis, A. V., and Jahr, C. E. (2002). Comparison of coupled and uncoupled currents during glutamate uptake by GLT-1 transporters. J. Neurosci. 22, 10153-10162. doi: 10.1523/JNEUROSCI.22-23-10153.2002

Bernardinelli, Y., Muller, D., and Nikonenko, I. (2014a). Review article astrocyte-synapse structural plasticity. Neural Plast. 2014:232105. doi: $10.1155 / 2014 / 232105$

Bernardinelli, Y., Randall, J., Janett, E., Nikonenko, I., König, S., Jones, E. V., et al. (2014b). Activity-dependent structural plasticity of perisynaptic astrocytic domains promotes excitatory synapse stability. Curr. Biol. 24, 1679-1688. doi: 10.1016/j.cub.2014.06.025

Bonfardin, V. D. J., Fossat, P., Theodosis, D. T., and Oliet, S. H. R. (2010). Glia-dependent switch of kainate receptor presynaptic action. J. Neurosci. 30, 985-995. doi: 10.1523/JNEUROSCI.3389-09.2010

Boudaba, C., Linn, D. M., Halmos, K. C., and Tasker, J. G. (2003). Increased tonic activation of presynaptic metabotropic glutamate receptors in the rat supraoptic nucleus following chronic dehydration. J. Physiol. 551, 815-823. doi: 10.1113/jphysiol.2003.042739
Bourne, J. N., and Harris, K. M. (2012). Coordination of size and number of excitatory and inhibitory synapses results in a balanced. Hippocampus 21, 354-373. doi: 10.1002/hipo.20768

Bourne, J. N., Kirov, S. A., Sorra, K. E., and Harris, K. M. (2007). Warmer preparation of hippocampal slices prevents synapse proliferation that might obscure LTP-related structural plasticity. Neuropharmacology 52, 55-59. doi: 10.1016/j.neuropharm.2006.06.020

Brancaccio, M., Patton, A. P., Chesham, J. E., Maywood, E. S., Hastings, M. H., Brancaccio, M., et al. (2017). Astrocytes control circadian timekeeping in the suprachiasmatic nucleus via glutamatergic signaling. Neuron 93, 1420.e5-1435.e5. doi: 10.1016/j.neuron.2017.02.030

Brasnjo, G., and Otis, T. S. (2001). Neuronal glutamate transporters control activation of postsynaptic metabotropic glutamate receptors and influence cerebellar long-term depression. Neuron 31, 607-616. doi: 10.1016/s08966273(01)00377-4

Brette, R. (2015). Philosophy of the spike: rate-based vs. spike-based theories of the brain. Front. Syst. Neurosci. 9:151. doi: 10.3389/fnsys.2015.00151

Briggs, C., Hirasawa, M., and Semba, K. (2018). Sleep deprivation distinctly alters glutamate transporter 1 apposition and excitatory transmission to orexin and MCH neurons. J. Neurosci. 38, 2505-2518. doi: 10.1523/JNEUROSCI.217917.2018

Chalifoux, J. R., and Carter, A. G. (2011). Glutamate spillover promotes the generation of NMDA spikes. J. Neurosci. 31, 16435-16446. doi: 10.1523/JNEUROSCI.2777-11.2011

Chapman, D., Theodosis, D., Montagnese, C., Poulain, D., and Morris, J. (1986). Osmotic stimulation causes structural plasticity of neurone-glia relationships of the oxytocin but not vasopressin secreting neurones in the hypothalamic supraoptic nucleus. Neuroscience 17, 679-686. doi: 10.1016/0306-4522(86)90039-4

Chaudhry, F. A., Lehre, K. P., van Lookeren Campagne, M., Ottersen, O. P., Danbolt, N. C., and Storm-Mathisen, J. (1995). Glutamate transporters in glial plasma membranes: highly differentiated localizations revealed by quantitative ultrastructural immunocytochemistry. Neuron 15, 711-720. doi: 10.1016/08966273(95)90158-2

Chen, W., Mahadomrongkul, V., Berger, U. V., Bassan, M., DeSilva, T., Tanaka, K., et al. (2004). The glutamate transporter GLT1a is expressed in excitatory axon terminals of mature hippocampal neurons. J. Neurosci. 24, 1136-1148. doi: 10.1523/JNEUROSCI.1586-03.2004

Clark, B. A., and Cull-Candy, S. G. (2002). Activity-dependent recruitment of extrasynaptic NMDA receptor activation at an AMPA receptor-only synapse. J. Neurosci. 22, 4428-4436. doi: 10.1523/JNEUROSCI.22-11-04428.2002

Clements, J. D., Lester, R. A., Tong, G., Jahr, C. E., and Westbrook, G. L. (1992). The time course of glutamate in the synaptic cleft. Science 258, 1498-1501. doi: 10.1126/science.1359647

Coddington, L., Rudolph, S., Vande Lune, P., Overstreet-Wadiche, L., and Wadiche, J. (2013). Spillover-mediated feedforward inhibition functionally segregates interneuron activity. Neuron 78, 1050-1062. doi: 10.1016/j.neuron. 2013.04.019

Conti, F., Debiasi, S., Minelli, A., Jeffrey, D., and Melone, M. (1998). EAAC1, a high-affinity glutamate tranporter, is localized to astrocytes and GABAergic neurons besides pyramidal cells in the rat cerebral cortex. Cereb. Cortex 8 , 108-116. doi: 10.1093/cercor/8.2.108

Cooper, L. N., and Bear, M. F. (2012). The BCM theory of synapse modification at 30: interaction of theory with experiment. Nat. Rev. Neurosci. 13, 798-810. doi: 10.1038/nrn3353

D'Errico, A., Prestori, F., and D'Angelo, E. (2009). Differential induction of bidirectional long-term changes in neurotransmitter release by frequencycoded patterns at the cerebellar input. J. Physiol. 587, 5843-5857. doi: 10.1113/jphysiol.2009.177162

Danbolt, N. C. (2001). Glutamate uptake. Prog. Neurobiol. 65, 1-105. doi: 10.1016/S0301-0082(00)00067-8

Danbolt, N. C., Furness, D. N., and Zhou, Y. (2016). Neuronal vs. glial glutamate uptake: resolving the conundrum. Neurochem. Int. 98, 29-45. doi: 10.1016/j. neuint.2016.05.009

Danbolt, N. C., Storm-Mathisen, J., and Kanner, B. I. (1992). An $\left[\mathrm{Na}^{+}+\right.$ $\mathrm{K}^{+}$] coupled L-glutamate transporter purified from rat brain is located in glial cell processes. Neuroscience 51, 295-310. doi: 10.1016/0306-4522(92) 90316-t 
deCharms, R. C., and Zador, A. (2000). Neural representation and the cortical code. Annu. Rev. Neurosci. 24, 1193-1216. doi: 10.1146/annurev.neuro. 23.1.613

Dehnes, Y., Chaudhry, F. A., Ullensvang, K., Lehre, K. P., Storm-Mathisen, J., and Danbolt, N. C. (1998). The glutamate transporter EAAT4 in rat cerebellar Purkinje cells: a glutamate-gated chloride channel concentrated near the synapse in parts of the dendritic membrane facing astroglia. J. Neurosci. 18, 3606-3619. doi: 10.1523/JNEUROSCI.18-10-03606.1998

Dembrow, N. C., Zemelman, B. V., and Johnston, D. (2015). Temporal dynamics of L5 dendrites in medial prefrontal cortex regulate integration versus coincidence detection of afferent inputs. J. Neurosci. 35, 4501-4514. doi: 10.1523/JNEUROSCI.4673-14.2015

Derouiche, A., and Frotscher, M. (1991). Astroglial processes around identified glutamatergic synapses contain glutamine synthetase: evidence for transmitter degradation. Brain Res. 552, 346-350. doi: 10.1016/0006-8993(91) 90103-3

Devaraju, P., Sun, M.-Y., Myers, T. L., Lauderdale, K., and Fiacco, T. A. (2013). Astrocytic group I mGluR-dependent potentiation of astrocytic glutamate and potassium uptake. J. Neurophysiol. 109, 2404-2414. doi: 10.1152/jn.00517.2012

Diamond, J. S., Bergles, D. E., and Jahr, C. E. (1998). Glutamate release monitored with astrocyte transporter currents during LTP. Neuron 21, 425-433. doi: 10.1016/s0896-6273(00)80551-6

Diamond, J. S., and Jahr, C. E. (1997). Transporters buffer synaptically released glutamate on a submillisecond time scale. J. Neurosci. 17, 4672-4687. doi: 10.1523/JNEUROSCI.17-12-04672.1997

Diamond, J. S., and Jahr, C. E. (2000). Synaptically released glutamate does not overwhelm transporters on hippocampal astrocytes during high-frequency stimulation. J. Neurophysiol. 83, 2835-2843. doi: 10.1152/jn.2000.83.5.2835

Durand-de Cuttoli, R., Mondoloni, S., Marti, F., Lemoine, D., Nguyen, C., Naudé, U., et al. (2018). Manipulating midbrain dopamine neurons and reward-related behaviors with light- controllable nicotinic acetylcholine receptors. Elife 7:e37487. doi: 10.7554/elife.37487

Dzubay, J. A., and Otis, T. S. (2002). Climbing fiber activation of metabotropic glutamate receptors on cerebellar purkinje neurons. Neuron 36, 1159-1167. doi: 10.1016/s0896-6273(02)01052-8

Eliasof, S., and Jahr, C. E. (1996). Retinal glial cell glutamate transporter is coupled to an anionic conductance. Proc. Natl. Acad. Sci. U S A 93, 4153-4158. doi: 10.1073/pnas.93.9.4153

Evans, R. C., Morera-Herreras, T., Cui, Y., Du, K., Sheehan, T., Kotaleski, J. H., et al. (2012). The effects of NMDA subunit composition on calcium influx and spike timing-dependent plasticity in striatal medium spiny neurons. PLoS Comput. Biol. 8:e1002493. doi: 10.1371/journal.pcbi.1002493

Fairman, W. A., Vandenberg, R. J., Arriza, J. L., Kavanaugh, M. P., and Amara, S. G. (1995). An excitatory amino-acid transporter with properties of a ligand-gated chloride channel. Nature 375, 599-603. doi: 10.1038/375 $599 \mathrm{a} 0$

Farries, M. A., Kita, H., and Wilson, C. J. (2010). Dynamic spike threshold and zero membrane slope conductance shape the response of subthalamic neurons to cortical input. J. Neurosci. 30, 13180-13191. doi: 10.1523/JNEUROSCI.190910.2010

Feldman, D. E. (2012). The spike-timing dependence of plasticity. Neuron 75, 556-571. doi: 10.1016/j.neuron.2012.08.001

Fino, E., Paillé, V., Cui, Y., Morera-Herreras, T., Deniau, J.-M., and Venance, L. (2010). Distinct coincidence detectors govern the corticostriatal spike timingdependent plasticity. J. Physiol. 588, 3045-3062. doi: 10.1113/jphysiol.2010. 188466

Fino, E., and Venance, L. (2011). Spike-timing dependent plasticity in striatal interneurons. Neuropharmacology 60, 780-788. doi: 10.1016/j.neuropharm. 2011.01.023

Fleming, T. M., Scott, V., Naskar, K., Joe, N., Brown, C. H., and Stern, J. E. (2011). State-dependent changes in astrocyte regulation of extrasynaptic NMDA receptor signalling in neurosecretory neurons. J. Physiol. 589, 3929-3941. doi: 10.1113/jphysiol.2011.207340

Furness, D. N., Dehnes, Y., Akhtar, A. Q., Rossi, D. J., Hamann, M., Grutle, N. J., et al. (2008). A quantitative assessment of glutamate uptake into hippocampal synaptic terminals and astrocytes: new insights into a neuronal role for excitatory amino acid transporter 2 (EAAT2). Neuroscience 157, 80-94. doi: 10.1016/j.neuroscience.2008.08.043
Furuta, A., Rothstein, J. D., and Martin, L. J. (1997). Glutamate transporter protein subtypes are expressed differentially during rat CNS development. J. Neurosci. 17, 8363-8375. doi: 10.1523/JNEUROSCI.17-21-08363.1997

Garcia-Segura, L. M., Luquín, S., Párducz, A., and Naftolin, F. (1994). Gonadal hormone regulation of glial fibrillary acidic protein immunoreactivity and glial ultrastructure in the rat neuroendocrine hypothalamus. Glia 10, 59-69. doi: $10.1002 /$ glia.440100108

Gasull-Camós, J., Tarrés-Gatius, M., Artigas, F., and Castañé, A. (2017). Glial GLT-1 blockade in infralimbic cortex as a new strategy to evoke rapid antidepressant-like effects in rats. Transl. Psychiatry 7:e1038. doi: 10.1038/tp. 2017.7

Gavrilov, N., Golyagina, I., Brazhe, A., Scimemi, A., Turlapov, V., and Semyanov, A. (2018). Astrocytic coverage of dendritic spines, dendritic shafts, and axonal boutons in hippocampal neuropil. Front. Cell. Neurosci. 12:248. doi: 10.3389/fncel.2018.00248

Genoud, C., Quairiaux, C., Steiner, P., Hirling, H., Welker, E., and Knott, G. W. (2006). Plasticity of astrocytic coverage and glutamate transporter expression in adult mouse cortex. PLoS Biol. 4:e343. doi: 10.1371/journal.pbio. 0040343

Harris, J. N., and Bourne, K. M. (2012). Nanoscale analysis of structural synaptic plasticity. Curr. Opin. Neurobiol. 22, 372-382. doi: 10.1016/j.conb.2011. 10.019

Helassa, N., Dürst, C. D., Coates, C., Kerruth, S., Arif, U., Schulze, C., et al. (2018). Ultrafast glutamate sensors resolve high-frequency release at Schaffer collateral synapses. Proc. Natl. Acad. Sci. U S A 115, 5594-5599. doi: 10.1073/pnas. 1720648115

Heller, J. P., and Rusakov, D. A. (2015). Morphological plasticity of astroglia: understanding synaptic microenvironment. Glia 63, 2133-2151. doi: 10.1002/glia.22821

Herberg, L. J., and Rose, I. C. (1990). Excitatory amino acid pathways in brain-stimulation reward. Behav. Brain Res. 39, 230-239. doi: 10.1016/01664328(90)90029-e

Holmseth, S., Scott, H. A., Real, K., Lehre, K. P., Leergaard, T. B., Bjaalie, J. G., et al. (2009). The concentrations and distributions of three $\mathrm{C}$-terminal variants of the GLT1 (EAAT2; slc1a2) glutamate transporter protein in rat brain tissue suggest differential regulation. Neuroscience 162, 1055-1071. doi: 10.1016/j. neuroscience.2009.03.048

Huang, Y. H., and Bergles, D. E. (2004). Glutamate transporters bring competition to the synapse. Curr. Opin. Neurobiol. 14, 346-352. doi: 10.1016/j.conb.2004. 05.007

Huang, Y. Y., and Kandel, E. R. (1998). Postsynaptic induction and PKA-dependent expression of LTP in the lateral amygdala. Neuron 21, 169-178. doi: 10.1016/s0896-6273(00)80524-3

Huang, Y. H., Sinha, S. R., Tanaka, K., Rothstein, J. D., and Bergles, D. E. (2004). Glutamate receptor-mediated excitation of hippocampal interneurons. J. Neurosci. 24, 4551-4559. doi: 10.1523/JNEUROSCI.5217-03.2004

Janak, P. H., and Tye, K. M. (2015). From circuits to behaviour in the amygdala. Nature 517, 284-292. doi: 10.1038/nature14188

John, C. S., Smith, K. L., Van't Veer, A., Gompf, H. S., Carlezon, W. A. Jr., Cohen, B. M., et al. (2012). Blockade of astrocytic glutamate uptake in the prefrontal cortex induces anhedonia. Neuropsychopharmacology 37, 2467-2475. doi: 10.1038/npp.2012.105

John, C. S., Sypek, E. I., Carlezon, W. A., Cohen, B. M., Öngür, D., and Bechtholt, A. J. (2015). Blockade of the GLT-1 transporter in the central nucleus of the amygdala induces both anxiety and depressive-like symptoms. Neuropsychopharmacology 40, 1700-1708. doi: 10.1038/npp.2015.16

Jones, T. A., Hawrylak, N., and Greenough, W. T. (1996). Rapid laminardependent changes in GFAP immunoreactive astrocytes in the visual cortex of rats reared in a complex environment. Psychoneuroendocrinology 21, 189-201. doi: 10.1016/0306-4530(95)00041-0

Karaman, I., Kizilay-Ozfidan, G., Karadag, C. H., and Ulugol, A. (2013). Lack of effect of ceftriaxone, a GLT-1 transporter activator, on spatial memory in mice. Pharmacol. Biochem. Behav. 108, 61-65. doi: 10.1016/j.pbb.2013.04.013

Karlsson, R. M., Tanaka, K., Heilig, M., and Holmes, A. (2008). Loss of glial glutamate and aspartate transporter (excitatory amino acid transporter 1) causes locomotor hyperactivity and exaggerated responses to psychotomimetics: rescue by haloperidol and metabotropic glutamate 2/3 agonist. Biol. Psychiatry 64, 810-814. doi: 10.1016/j.biopsych.2008.05.001 
Karlsson, R. M., Tanaka, K., Saksida, L. M., Bussey, T. J., Heilig, M., and Holmes, A. (2009). Assessment of glutamate transporter GLAST (EAAT1)-deficient mice for phenotypes relevant to the negative and executive/cognitive symptoms of schizophrenia. Neuropsychopharmacology 34, 1578-1589. doi: 10.1038/npp. 2008.215

Katagiri, H., Tanaka, K., and Manabe, T. (2001). Requirement of appropriate glutamate concentrations in the synaptic cleft for hippocampal LTP induction. Eur. J. Neurosci. 14, 547-553. doi: 10.1046/j.0953-816x.2001. 01664.x

Kawamura, Y., Manita, S., Nakamura, T., Inoue, M., Kudo, Y., and Miyakawa, H. (2004). Glutamate release increases during mossy-CA3 LTP but not during Schaffer-CA1 LTP. Eur. J. Neurosci. 19, 1591-1600. doi: 10.1111/j.1460-9568. 2004.03258.x

Khakh, B. S., and Sofroniew, M. V. (2015). Diversity of astrocyte functions and phenotypes in neural circuits. Nat. Neurosci. 18, 942-952. doi: 10.1038/ nn. 4043

Kobayashi, K., Manabe, T., and Takahashi, T. (1996). Presynaptic long-term depression at the hippocampal mossy fiber-CA3 synapse. Science 273, 648-650. doi: 10.1126/science.273.5275.648

Kramer, R. H., Mourot, A., and Adesnik, H. (2013). Optogenetic pharmacology for control of native neuronal signaling proteins. Nat. Neurosci. 16, 816-823. doi: $10.1038 / \mathrm{nn} .3424$

Kullmann, D. M., and Asztely, F. (1998). Extrasynaptic glutamate spillover in the hippocampus: evidence and implications. Trends Neurosci. 21, 8-14. doi: 10.1016/s0166-2236(97)01150-8

Kullmann, D. M., Erdemli, G., and Asztély, F. (1996). LTP of AMPA and NMDA receptor-mediated signals: evidence for presynaptic expression and extrasynaptic glutamate spill-over. Neuron 17, 461-474. doi: 10.1016/s08966273(00)80178-6

Kullmann, D. M., and Lamsa, K. P. (2007). Long-term synaptic plasticity in hippocampal interneurons. Nat. Rev. Neurosci. 8, 687-699. doi: $10.1038 / \mathrm{nrn} 2207$

Lavialle, M., Begue, A., Papillon, C., and Vilaplana, J. (2001). Modifications of retinal afferent activity induce changes in astroglial plasticity in the hamster circadian clock. Glia 100, 88-100. doi: 10.1002/glia.1044

Lee, Y., Gaskins, D., Anand, A., and Shekhar, A. (2007). Glia mechanisms in mood regulation: a novel model of mood disorders. Psychopharmacology 191, 55-65. doi: 10.1007/s00213-006-0652-4

Lehre, K. P., Levy, L. M., Storm-mathisen, J., Ottersen, O. P., and Danbolt, N. C. (1995). Differential expression of two glial glutamate transporters in the rat brain: quantitative and Immunocytochemical observations. J. Neurosci. 15, 1835-1853. doi: 10.1523/JNEUROSCI.15-03-01835.1995

Lehre, K. P., and Rusakov, D. A. (2002). Asymmetry of glia near central synapses favors presynaptically directed glutamate escape. Biophys. J. 83, 125-134. doi: 10.1016/s0006-3495(02)75154-0

Levenson, J., Weeber, E., Selcher, J. C., Kategaya, L. S., Sweatt, J. D., and Eskin, A. (2002). Long-term potentiation and contextual fear conditioning increase neuronal glutamate uptake. Nat. Neurosci. 5, 155-161. doi: 10.1038/ nn791

Levy, L. M., Warr, O., and Attwell, D. (1998). Stoichiometry of the glial glutamate transporter GLT-1 expressed inducibly in a Chinese hamster ovary cell line selected for low endogenous $\mathrm{Na}^{+}$-dependent glutamate uptake. J. Neurosci. 18, 9620-9628. doi: 10.1523/JNEUROSCI.18-23-09620.1998

Liaw, W., Stephens, R. L. Jr., Binns, B. C., Chu, Y., Sepkuty, J. P., Johns, R. A., et al. (2005). Spinal glutamate uptake is critical for maintaining normal sensory transmission in rat spinal cord. Pain 115, 60-70. doi: 10.1016/j.pain.2005. 02.006

Lüscher, C., Malenka, R. C., and Nicoll, R. A. (1998). Monitoring glutamate release during LTP with glial transporter currents. Neuron 21, 435-441. doi: 10.1016/s0896-6273(00)80552-8

Lushnikova, I., Skibo, G., Muller, D., and Nikonenko, I. (2009). Synaptic potentiation induces increased glial coverage of excitatory synapses in CA1 hippocampus. Hippocampus 19, 753-762. doi: 10.1002/hipo.20551

Malenka, R. C., and Bear, M. F. (2004). LTP and LTD: an embarrassment of riches. Neuron 44, 5-21. doi: 10.1016/j.neuron.2004.09.012

Marvin, J., Borghuis, B., Tian, L., Cichon, J., Harnett, M., Akerboom, J., et al. (2013). An optimized fluorescent probe for visualizing glutamate neurotransmission. Nat. Methods 2, 162-170. doi: 10.1038/nmeth.2333
Massey, P. V., Johnson, B. E., Moult, P. R., Auberson, Y. P., Brown, M. W., Molnar, E., et al. (2004). Differential roles of NR2A and NR2B-containing NMDA receptors in cortical long-term potentiation and long-term depression. J. Neurosci. 24, 7821-7828. doi: 10.1523/JNEUROSCI.1697-04.2004

Matos-Ocasio, F., Hernández-López, A., and Thompson, K. J. (2014). Ceftriaxone, a GLT-1 transporter activator, disrupts hippocampal learning in rats. Pharmacol. Biochem. Behav. 122, 118-121. doi: 10.1016/j.pbb.2014.03.011

Medvedev, N., Popov, V., Henneberger, C., Kraev, I., Rusakov, D. A., and Stewart, M. G. (2014). Glia selectively approach synapses on thin dendritic spines. Philos. Trans. R. Soc. B Biol. Sci. 369:20140047. doi: 10.1098/rstb. 2014.0047

Melone, M., Bellesi, M., and Conti, F. (2009). Synaptic localization of GLT-1a in the rat somatic sensory cortex. Glia 57, 108-117. doi: 10.1002/glia. 20744

Melone, M., Bellesi, M., Ducati, A., Iacoangeli, M., and Conti, F. (2011). Cellular and synaptic localization of EAAT2a in human cerebral cortex. Front. Neuroanat. 4:151. doi: 10.3389/fnana.2010.00151

Min, M., Rusakov, D. A., and Kullmann, D. M. (1998). Activation of AMPA, kainate, and metabotropic receptors at hippocampal mossy fiber synapses: role of glutamate diffusion. Neuron 21, 561-570. doi: 10.1016/s08966273(00)80566-8

Minelli, A., Barbaresi, P., Reimer, R. J., Edwards, R. H., and Conti, F. (2001). The glial glutamate transporter GLT-1 is localized both in the vicinity of and at distance from axon terminals in the rat cerebral cortex. Neuroscience 108, 51-59. doi: 10.1016/s0306-4522(01)00375-x

Mineur, Y. S., Picciotto, M. R., and Sanacora, G. (2007). Antidepressant-like effects of ceftriaxone in male C57BL/6J mice. Biol. Psychiatry 61, 250-252. doi: 10.1016/j.biopsych.2006.04.037

Murphy-Royal, C., Dupuis, J. P., Varela, J. A., Panatier, A., Pinson, B., Baufreton, J., et al. (2015). Surface diffusion of astrocytic glutamate transporters shapes synaptic transmission. Nat. Neurosci. 18, 219-226. doi: 10.1038/ nn. 3901

Naskar, K., and Stern, J. E. (2014). A functional coupling between extrasynaptic NMDA receptors and A-type $\mathrm{K}^{+}$channels under astrocyte control regulates hypothalamic neurosecretory neuronal activity. J. Physiol. 592, 2813-2827. doi: 10.1113/jphysiol.2014.270793

Nicoll, R., and Malenka, R. (1995). Contrasting properties of two forms of long-term potentiation in the hippocampus. Nature 377, 115-118. doi: $10.1038 / 377115 \mathrm{a} 0$

Oliet, S. H., Piet, R., and Poulain, D. A. (2001). Control of glutamate clearance and synaptic efficacy by glial coverage of neurons. Science 292, 923-926. doi: 10.1126/science. 1059162

Omrani, A., Melone, M., Bellesi, M., Safiulina, V., Aida, T., Tanaka, K., et al. (2009). Up-regulation of GLT-1 severely impairs LTD at mossy fibre-CA3 synapses. J. Physiol. 587, 4575-4588. doi: 10.1113/jphysiol.2009.177881

Owe, S. G., Marcaggi, P., and Attwell, D. (2006). The ionic stoichiometry of the GLAST glutamate transporter in salamander retinal glia. J. Physiol. 577, 591-599. doi: 10.1113/jphysiol.2006.116830

Panatier, A., Gentles, S. J., Bourque, C. W., and Oliet, S. H. R. (2006a). Activity-dependent synaptic plasticity in the supraoptic nucleus of the rat hypothalamus. J. Physiol. 573, 711-721. doi: 10.1113/jphysiol.2006. 109447

Panatier, A., Theodosis, D. T., Mothet, J., Touquet, B., Pollegioni, L., Poulain, D. A., et al. (2006b). Glia-derived D-serine controls NMDA receptor activity and synaptic memory. Cell 125, 775-784. doi: 10.1016/j.cell.2006. 02.051

Pannasch, U., Freche, D., Dallérac, G., Ghézali, G., Escartin, C., Ezan, P., et al. (2014). Connexin 30 sets synaptic strength by controlling astroglial synapse invasion. Nat. Neurosci. 17, 549-558. doi: 10.1038/nn.3662

Paoletti, P., Bellone, C., and Zhou, Q. (2013). NMDA receptor subunit diversity: impact on receptor properties, synaptic plasticity and disease. Nat. Rev. Neurosci. 14, 383-400. doi: 10.1038/nrn3504

Parsons, M. P., Vanni, M. P., Woodard, C. L., Kang, R., Murphy, T. H., and Raymond, L. A. (2016). Real-time imaging of glutamate clearance reveals normal striatal uptake in Huntington disease mouse models. Nat. Commun. 7:11251. doi: 10.1038/ncomms11251

Peghini, P., Janzen, J., and Stoffel, W. (1997). Glutamate transporter EAAC1-deficient mice develop dicarboxylic aminoaciduria and behavioral 
abnormalities but no neurodegeneration. EMBO J. 16, 3822-3832. doi: 10.1093/emboj/16.13.3822

Perlmutter, L. S., Tweedle, C. D., and Hatton, G. I. (1985). Neuronal/glial plasticity in the supraoptic dendritic zone in response to acute and chronic dehydration. Brain Res. 361, 225-232. doi: 10.1016/0006-8993(85)91293-4

Petr, G. T., Sun, Y., Frederick, X. N. M., Zhou, Y., Dhamne, S. C., Hameed, X. M. Q., et al. (2015). Conditional deletion of the glutamate transporter GLT-1 reveals that astrocytic GLT-1 protects against fatal epilepsy while neuronal GLT-1 contributes significantly to glutamate uptake into synaptosomes. J. Neurosci. 35, 5187-5201. doi: 10.1523/jneurosci.425514.2015

Piet, R., Vargová, L., Syková, E., Poulain, D. A., and Oliet, S. H. R. (2004). Physiological contribution of the astrocytic environment of neurons to intersynaptic crosstalk. Proc. Natl. Acad. Sci. U S A 101, 2151-2155. doi: 10.1073/pnas.0308408100

Pita-Almenar, J. D., Collado, M. S., Colbert, C. M., and Eskin, A. (2006). Different mechanisms exist for the plasticity of glutamate reuptake during early long-term potentiation (LTP) and late LTP. J. Neurosci. 26, 10461-11071. doi: 10.1523/jneurosci.2579-06.2006

Pita-Almenar, J. D., Zou, S., Colbert, C. M., and Eskin, A. (2005). Relationship between increase in astrocytic GLT-1 glutamate transport and late-LTP. Learn. Mem. 19, 615-626. doi: 10.1101/lm.023259.111

Randić, M., Jiang, M. C., and Cerne, R. (1993). Long-term potentiation and long-term depression of primary afferent neurotransmission in the rat spinal cord. J. Neurosci. 13, 5228-5241. doi: 10.1523/jneurosci.13-12-05 228.1993

Reagan, L. P., Rosell, D. R., Wood, G. E., Spedding, M., Mun, C., Rothstein, J., et al. (2004). Chronic restraint stress up-regulates GLT-1 mRNA and protein expression in the rat hippocampus: reversal by tianeptine. Proc. Natl. Acad. Sci. U S A 101, 2179-2184. doi: 10.1073/pnas.0307294101

Reichelt, W., and Knöpfel, T. (2002). Glutamate uptake controls expression of a slow postsynaptic current mediated by mGluRs in cerebellar Purkinje cells. J. Neurophysiol. 87, 1974-1980. doi: 10.1152/jn.00704.2001

Rimmele, T. S., and Rosenberg, P. A. (2016). GLT-1: the elusive presynaptic glutamate transporter. Neurochem. Int. 98, 19-28. doi: 10.1016/j.neuint.2016. 04.010

Rollenhagen, A., Sätzler, K., Rodríguez, E. P., Jonas, P., Frotscher, M., and Lübke, J. H. R. (2007). Structural determinants of transmission at large hippocampal mossy fiber synapses. J. Neurosci. 27, 10434-10444. doi: 10.1523/JNEUROSCI.1946-07.2007

Rothstein, J. D., Levey, A. I., Dykes-hoberg, M., Jin, L., Wu, D., Nash, N., et al. (1994). localization of neuronal and glial glutamate transporters. Neuron 13, 713-725. doi: 10.1016/0896-6273(94)90038-8

Rothstein, J. D., Patel, S., Regan, M. R., Haenggeli, C., Huang, Y. H., Bergles, D. E., et al. (2005). Beta-lactam antibiotics offer neuroprotection by increasing glutamate transporter expression. Nature 433, 73-77. doi: 10.1038/nature03180

Rudolph, M., and Destexhe, A. (2003). Tuning neocortical pyramidal neurons between integrators. J. Comput. Neurosci. 14, 239-251. doi: 10.1023/A:1023245625896

Rusakov, D. A., and Kullmann, D. M. (1998). Extrasynaptic glutamate diffusion in the hippocampus: ultrastructural constraints, uptake, and receptor activation. J. Neurosci. 18, 3158-3170. doi: 10.1523/jneurosci.18-09-03158.1998

Safo, P., and Regehr, W. G. (2008). Timing dependence of the induction of cerebellar LTD patrick. Neuropharmacology 54, 213-218. doi: 10.1016/j. neuropharm.2007.05.029

Scanziani, M., Salin, P., Vogt, K., Malenka, R., and Nicoll, R. (1997). Use-dependent increases in glutamate concentration activate presynaptic metabotropic glutamate receptors. Nature 385, 630-634. doi: 10.1038/38 $5630 \mathrm{a} 0$

Schmitz, D., Mellor, J., Breustedt, J., and Nicoll, R. A. (2003). Presynaptic kainate receptors impart an associative property to hippocampal mossy fiber long-term potentiation. Nat. Neurosci. 6, 1058-1063. doi: 10.1038/nn1116

Schneider, N., Cordeiro, S., Machtens, J. P., Braams, S., Rauen, T., and Fahlke, C. (2014). Functional properties of the retinal glutamate transporters GLT-1c and EAAT 5. J. Biol. Chem. 289, 1815-1824. doi: 10.1074/jbc.m113.517177

Scimemi, A., Fine, A., Kullmann, D. M., and Rusakov, D. A. (2004). NR2Bcontaining receptors mediate cross talk among hippocampal synapses. J. Neurosci. 24, 4767-4777. doi: 10.1523/jneurosci.0364-04.2004
Scimemi, A., Tian, H., and Diamond, J. S. (2009). Neuronal transporters regulate glutamate clearance, NMDA receptor activation, and synaptic plasticity in the hippocampus. J. Neurosci. 29, 14581-14595. doi: 10.1523/jneurosci.484509.2009

Sgritta, M., Prestori, F., and D'Angelo, E. (2017). Hebbian spike-timing dependent plasticity at the cerebellar input stage. J. Neurosci. 37, 2809-2823. doi: 10.1523/jneurosci.2079-16.2016

Shen, Y., and Linden, D. J. (2005). Long-term potentiation of neuronal glutamate transporters. Neuron 46, 715-722. doi: 10.1016/j.neuron.2005.04.033

Sjöström, P. J., Rancz, A., Roth, A., and Häusser, M. (2008). Dendritic excitability and synaptic plasticity. Physiol. Rev. 88, 769-840. doi: 10.1152/physrev. 00016.2007

Suvrathan, A., Payne, H. L., and Raymond, J. L. (2016). Timing rules for synaptic plasticity matched to behavioral function. Neuron 92, 959-967. doi: 10.1016/j. neuron.2016.10.022

Szapiro, G., and Barbour, B. (2007). Multiple climbing fibers signal to molecular layer interneurons exclusively via glutamate spillover. Nat. Neurosci. 10, 735-742. doi: 10.1038/nn1907

Tanaka, J., Ichikawa, R., Watanabe, M., Tanaka, K., and Inoue, Y. (1997). Extrajunctional localization of glutamate transporter EAAT4 at excitatory Purkinje cell synapses. Neuroreport 8, 2461-2464. doi: 10.1097/00001756-19970728000010

Tatsumi, K., Okuda, H., Morita-Takemura, S., Tanaka, T., Isonishi, A., Shinjo, T., et al. (2016). Voluntary exercise induces astrocytic structural plasticity in the globus pallidus. Front. Cell. Neurosci. 10:165. doi: 10.3389/fncel.2016.00165

Theodosis, D. T., and Poulain, D. A. (1993). Activity-dependent neuronal-glial and synaptic plasticity in the adult mammalian hypothalamus. Neuroscience 57 , 501-535. doi: 10.1016/0306-4522(93)90002-w

Tian, S.-W., Yu, X.-D., Cen, L., and Xiao, Z.-Y. (2019). Glutamate transporter GLT1 inhibitor dihydrokainic acid impairs novel object recognition memory performance in mice. Physiol. Behav. 199, 28-32. doi: 10.1016/j.physbeh.2018. 10.019

Tong, G., and Jahr, E. (1994). Block of glutamate transporters potentiates synaptic excitation. Neuron 13, 1195-1203. doi: 10.1016/0896-6273(94)90057-4

Tsvetkov, E., Carlezon, W. A., Benes, F. M., Kandel, E. R., and Bolshakov, V. Y. (2002). Fear conditioning occludes LTP-induced presynaptic enhancement of synaptic transmission in the cortical pathway to the lateral amygdala. Neuron 34, 289-300. doi: 10.1016/s0896-6273(02)00645-1

Tsvetkov, E., Shin, R. M., and Bolshakov, V. Y. (2004). Glutamate uptake determines pathway specificity of long-term potentiation in the neural circuitry of fear conditioning. Neuron 41, 139-151. doi: 10.1016/s0896-6273(03) 00800-6

Tzingounis, A. V., and Wadiche, J. I. (2007). Glutamate transporters: confining runaway excitation by shaping synaptic transmission. Nat. Rev. Neurosci. 8 , 935-947. doi: 10.1038/nrn2274

Valtcheva, S., and Venance, L. (2016). Astrocytes gate Hebbian synaptic plasticity in the striatum. Nat. Commun. 7:13845. doi: 10.1038/ncomms 13845

Vandenberg, R. J., and Ryan, R. M. (2013). Mechanisms of glutamate transport. Physiol. Rev. 93, 1621-1657. doi: 10.1152/physrev.00007.2013

Veruki, M. L., Mørkve, S. H., and Hartveit, E. (2006). Activation of a presynaptic glutamate transporter regulates synaptic transmission through electrical signaling. Nat. Neurosci. 9, 1388-1396. doi: 10.1038/nn1793

Vogels, T. P., Froemke, R. C., Doyon, N., Gilson, M., Haas, J. S., Liu, R., et al. (2013). Inhibitory synaptic plasticity: spike timing-dependence and putative network function. Front. Neural Circuits 7:119. doi: 10.3389/fncir.2013.00119

Wadiche, J. I., Amara, S. G., and Kavanaugh, M. P. (1995). Ion fluxes associated with excitatory amino acid transport. Neuron 15, 721-728. doi: 10.1016/08966273(95)90159-0

Wadiche, J. I., and Jahr, C. E. (2005). Patterned expression of Purkinje cell glutamate transporters controls synaptic plasticity. Nat. Neurosci. 8, 1329-1334. doi: $10.1038 / \mathrm{nn} 1539$

Wadiche, J. I., and Kavanaugh, M. P. (1998). Macroscopic and microscopic properties of a cloned glutamate transporter/chloride channel. J. Neurosci. 18, 7650-7661. doi: 10.1523/jneurosci.18-19-07650.1998

Wang, Z., Park, S. H., Zhao, H., Peng, S., and Zuo, Z. (2014). A critical role of glutamate transporter type 3 in the learning and memory of mice. Neurobiol. Learn. Mem. 114, 70-80. doi: 10.1016/j.nlm.2014.04.012 
Wang, Z.-Y., Zhang, Y.-Q., and Zhao, Z.-Q. (2006). Inhibition of tetanically sciatic stimulation-induced LTP of spinal neurons and Fos expression by disrupting glutamate transporter GLT- 1. Neuropharmacology 51, 764-772. doi: 10.1016/j. neuropharm.2006.05.024

Watase, K., Hashimoto, K., Kano, M., Yamada, K., Watanabe, M., Inoue, Y., et al. (1998). Motor discoordination and increased susceptibility to cerebellar injury in GLAST mutant mice. Eur. J. Neurosci. 10, 976-988. doi: 10.1046/j.1460-9568. 1998.00108.x

Wong, T. P., Howland, J. G., Robillard, J. M., Ge, Y., Yu, W., Titterness, A. K., et al. (2007). Hippocampal long-term depression mediates acute stress-induced spatial memory retrieval impairment. Proc. Natl. Acad. Sci. U S A 104, 11471-11476. doi: 10.1073/pnas.0702308104

Xu-Friedman, M. A., Harris, K. M., and Regehr, W. G. (2001). Threedimensional comparison of ultrastructural characteristics at depressing and facilitating synapses onto cerebellar purkinje cells. J. Neurosci. 21, 6666-6672. doi: 10.1523/JNEUROSCI.21-17-06666.2001

Xu-Friedman, M. A., and Regehr, W. G. (2003). Ultrastructural contributions to desensitization at cerebellar mossy fiber to granule cell synapses. J. Neurosci. 23, 2182-2192. doi: 10.1523/jneurosci.23-06-021 82.2003

Yang, C.-H., Huang, C.-C., and Hsu, K.-S. (2005). Behavioral stress enhances hippocampal CA1 long-term depression through the blockade of the glutamate uptake. J. Neurosci. 25, 4288-4293. doi: 10.1523/jneurosci.040605.2005
Yao, L., Grand, T., Hanson, J., Paoletti, P., and Zhou, Q. (2018). Higher ambient synaptic glutamate at inhibitory versus excitatory neurons differentially impacts NMDA receptor activity. Nat. Commun. 9:4000. doi: 10.1038/s41467018-06512-7

Yokoi, M., Kobayashi, K., Manabe, T., Takahashi, T., Sakaguchi, I., Katsuura, G., et al. (1996). Impairment of hippocampal mossy fiber LTD in mice lacking mGluR2. Science 273, 645-647. doi: 10.1126/science.273.5275.645

Zerangue, N., and Kavanaugh, M. P. (1996). Flux coupling in a neuronal glutamate transporter. Nature 383, 634-637. doi: 10.1038/383634a0

Zheng, K., Scimemi, A., and Rusakov, D. A. (2008). Receptor actions of synaptically released glutamate: the role of transporters on the scale from nanometers to microns. Biophys. J. 95, 4584-4596. doi: 10.1529/biophysj.108. 129874

Conflict of Interest Statement: The authors declare that the research was conducted in the absence of any commercial or financial relationships that could be construed as a potential conflict of interest.

Copyright (C) 2019 Valtcheva and Venance. This is an open-access article distributed under the terms of the Creative Commons Attribution License (CC BY). The use, distribution or reproduction in other forums is permitted, provided the original author(s) and the copyright owner(s) are credited and that the original publication in this journal is cited, in accordance with accepted academic practice. No use, distribution or reproduction is permitted which does not comply with these terms. 